\title{
Working
}

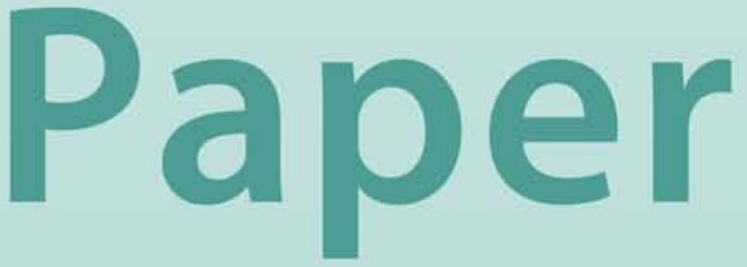




\title{
How Does the Introduction of Health Insurance Change the Equity of Health Care Provision in Bulgaria?
}

\author{
Nora Markova
}




\title{
IMF Working Paper
}

\author{
IMF Institute
}

\section{How Does the Introduction of Health Insurance Change the Equity of Health Care Provision in Bulgaria? ${ }^{1}$}

\author{
Prepared by Nora Markova ${ }^{2}$
}

Authorized for distribution by Andrew Feltenstein

December 2006

\begin{abstract}
This Working Paper should not be reported as representing the views of the IMF. The views expressed in this Working Paper are those of the author(s) and do not necessarily represent those of the IMF or IMF policy. Working Papers describe research in progress by the author(s) and are published to elicit comments and to further debate.

The study examines the effect of health care reform in Bulgaria in 1999 on the equity of health care financing. It explores the distribution of different types of health care financing by income. Furthermore, it separates the financial and social reasons for these differences, dividing them into economic and social inequalities. It suggests a method of distinguishing between financially based and "exclusion based" reasons for having progressive/regressive health care financing. Moreover, it looks at the social factors that shape health expenditure patterns and identifies those social characteristics that lead to exclusion from the health care system.

JEL Classification Numbers: I1, H5

Keywords: health care financing, equity in health care financing, income inequality, redistribution

Author’s E-Mail Address: nora.markova@applied-social-studies.oxford.ac.uk

\footnotetext{
${ }^{1}$ This paper derives from research grants from International Monetary Fund and the GDN/CERGE-EI Regional Research Competition. I am also grateful to Eddy van Doorslaer and Owen O'Donnell for their methodological support and to Adam Wagstaff, Stepan Jurajda, and Abdo Yazbeck for their helpful comments on the earlier versions of the paper.

${ }^{2}$ University of Oxford, International Monetary Fund.
} 


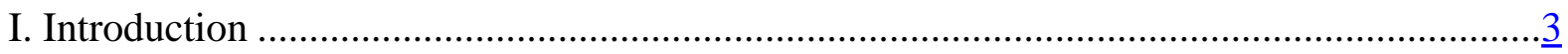

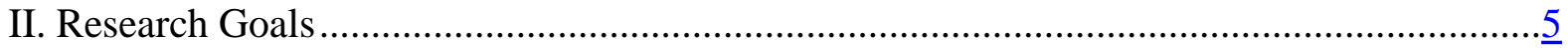

III. Data Sources and Methodology …...................................................................

A. Health Care Expenses and Income Distribution ............................................... $\underline{6}$

B. Income, Gini Coefficients, and Equivalency Scale ......................................... $\underline{8}$

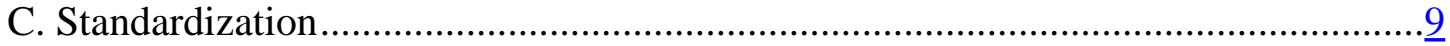

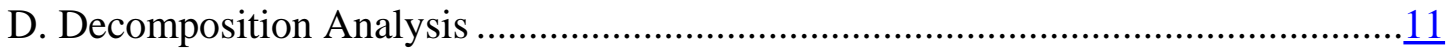

E. Benefit Incidence Analysis ................................................................. $\frac{13}{13}$

F. Poverty Impact of Health Care Payments..................................................... 13

IV. Results

A. Ill Health and Health Care Expenditure ..................................................... $\frac{15}{17}$

B. Income Distribution and Health Care Expenditure .........................................

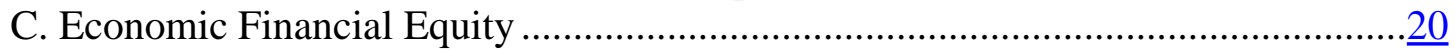

D. Influence of the Social Status on the Financial Equity ...................................

E. Health Care Service Utilization and Financial Equity .................................... $\frac{25}{27}$

F. Redistributive Effect of Health Care Payments .............................................. 27

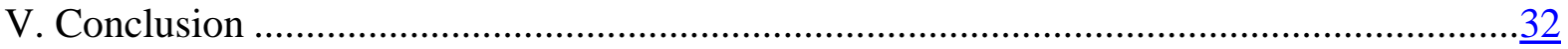

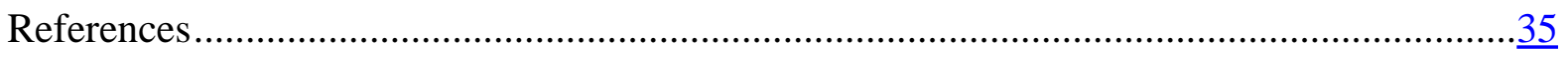

Tables

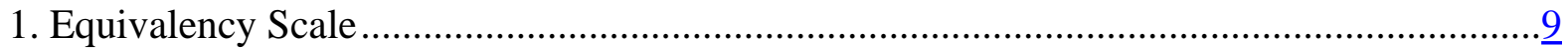

2. Gini, Concentration, and Kakwani Coefficients ....................................................... $\frac{18}{21}$

3. Gini, Income-Driven Concentration, and Economic Equity Coefficients .........................

4. Elasticity, Z Concentration Coefficients, and Their Contribution to C ............................24

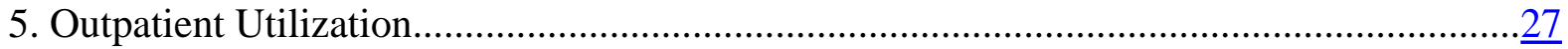

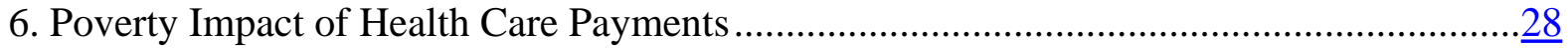

7. Catastrophic Health Care Payments............................................................................ 31

Figures

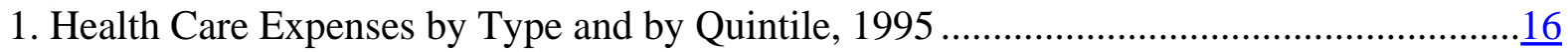

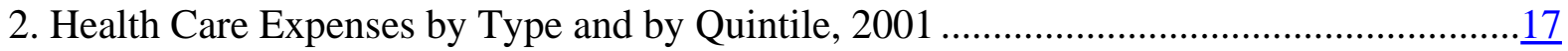

3. Lorenz and Concentration Curves, 1995 .............................................................. 19

4. Lorenz and Concentration Curves, 2001 .................................................................. $\frac{19}{22}$

5. Influence of the Different Factors on the Concentration Index of health OOP, $1995 \ldots \ldots \ldots .22$

6. Influence of the Different Factors on the Concentration Index of health OOP, 2001 .........23

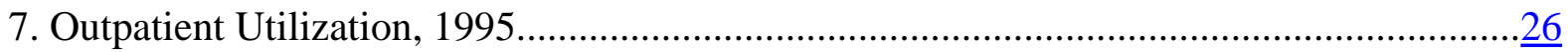

8. Outpatient Utilization, 2001...........................................................................

9. Pen's Parade of Pre and Post Health Care Payment's Income, 1995 .................................29

10. Pen's Parade of Pre and Post Health Care Payment's Income, 2001 ............................... 29

11. Share of Income Spent on Health Care - Total and OOP ........................................... $\underline{30}$ 


\section{INTRODUCTION}

Since the start of the transition period in Bulgaria in 1989, all social systems have undergone dramatic changes. These changes have had a significant influence on all of the factors determining the population's health. These factors may have arisen from sources outside of the health care system, such as household and community-related factors and government policy, as well as within the health care system itself. The process of transition has increased the social inequalities in the society by bringing a vast part of the population into poverty and at the same time shattering social security systems. Moreover, Bulgaria's transition phase has exhibited particularly negative effect on the health care sector, including various quality, equity, and efficiency problems and a substantial decrease in health outcomes (Koulaksazov, Todorova, and Hristova, 2003).

During the 1990s the health sector in Bulgaria continued to be characterized by the Semashko model of central planning (inherited from the communist era). The system was financed by general taxation, with public ownership and management of health care facilities. The universal entitlement to health care had to be delivered by a health care system which was increasingly inefficient and underfinanced. In addition, the political and economic crisis in the 1990s slowed reform of the health care system, resulting in financial malfunctioning within the sector, including increased public debt for health entities and a glut of corruption and informal payments. All these factors led to the collapse of comprehensive health care and left the most vulnerable part of the population without access to the health care system.

In order to understand the equity challenge for health care reform, this paper will highlight the most relevant processes preceding its start. Economically, Bulgaria has gone through several shocks during the transition period. The country experienced economic crisis in 1996-97, including hyperinflation in 1997. The living standard of the population dropped substantially. This crisis had several consequences for the process of health care delivery, including diminishing the ability of the system to provide health care and increasing the need for it.

Traditionally, in communist countries the salaries of medical personnel were kept at 7080 percent of the average salary, which did not change after the transition (Thompson and Witter, 2000). As a reaction to underpayment, physicians have been topping up their income with under-the-table payments for their work. Surveys on informal payments for health services in 1998-99 show up to 51 percent of the respondents paying for services which are officially free (Balabanova and McKee, 2002a; Ministry of Health, 2001). In addition, the lack of affordable treatments and drugs has been a serious issue for the population. In 1997 , 16 percent of the respondents of a survey stated that when ill they had not consulted a doctor because they could not afford it (Balabanova and McKee, 2002b).

Moreover, there was a rise in unemployment. The unemployment rate reached 15.0 percent in the urban areas and 17.3 percent in the rural areas in 1997 (Ministry of Health, 2001). The impoverishment of the population led to income levels at which the expenses for food were 40 percent and socioeconomic inequalities were rising (Atanasov and others, 2002, p. 15). This brought a large proportion of the society into poverty and dependence on state welfare. 
Comparative studies show that for the low-income countries, increases in social inequalities influence health inequalities and therefore general health (Smith and Egger, 1996, p. 446; Marmot, 2001, p. 157).

Furthermore, with the increase in poverty, the population exhibited more unhealthy behaviors. Uitenbroek, Kerekovska, and Festchieva (1996) explained this phenomenon in the transition countries with the focus of the population on increasing socioeconomic problems. Similarly, governmental policy could not pay the respective attention to lifestyle-related problems because of the priority of macroeconomic reform policies (Balabanova, Bobak, and McKee, 1998). These factors led to a decline of health status. Simultaneously, the aging of the population increased the number of people who needed health care and at the same time could not afford to pay for it. The worsening health status of the population, combined with both impoverishment and an increase in out-of-pocket payments for health care, pointed toward serious equity issues in the provision of health care.

Health care reform was introduced at the end of the 1990s. In 1999 there were worsening health and health service problems, decreasing authority of the medical professionals, and enormous tensions in the system as a whole. Furthermore, the financial protection in the health care sector was severely undermined and there was lack of cooperation with the other social sectors. The constitutional rights of citizens to "medical insurance guaranteeing them affordable medical care, and to free medical care in accordance with conditions and procedures established by law" (Constitution of Republic of Bulgaria, 1991 Article 52, s.a. 1) were disregarded.

In the existing literature there are detailed descriptions of the health care reforms, the most comprehensive of which is the National Health Strategy (Ministry of Health, 2001). This study will only outline those elements which have a direct impact on the equity of health care provision. The reforms introduced a system of compulsory health insurance. It is financed by 6 percent hypothecated health tax on the income. For the nonincome-earners the tax is paid accordingly by different social security systems, so that ideally the whole population is covered. Nevertheless, the bureaucratic process of unemployment registration has left a significant part of this group in an uninsured position. For some people the resulting financial obligations have become a serious financial burden. In addition, there is a ceiling for the maximum health care contribution, making the tax very regressive for the high earners.

At the point of delivery of health care, there is a fee-for-service payment in the outpatient sector and per diem payment in the inpatient sector. Additionally, regardless of significant growth in public expenses for pharmaceuticals, patients pay for the majority of their drugs out-of-pocket (OOP). Health care facilities were decentralized, and many were privatized in order to stimulate competition, leaving some strategic areas under governmental control. The goal of the reform is to improve the "health of the nation by building pluralism, democracy, accessibility, equity, solidarity, and shared responsibility for health" (Ministry of Health, 2001). As in most of the other transition countries, social insurance was introduced with the expectation that it would generate additional revenues for the health care system (Thompson and Witter, 2000). Still, these revenues have been growing slowly in Bulgaria and at the same time that other sources of financing have been significantly reduced (Hutton, 2002). As 
a result, the general health expenditures in the country did not rise as expected. They are still below 4.5 percent of GDP, although the reform plan projected that they would reach 6 percent by 2006 (Ministry of Health, 2001).

The problems associated with the health sector are highly dependent on global political, economic, and social processes. Therefore, the ability of the health sector to provide equitable health care during the transition period largely depends on the trends of socioeconomic inequalities. Economic crises and lack of financing have focused the attention of the reform on increasing the efficiency of services, which is seen by many to be detrimental to equity (Van Doorslaerm, Wagstaff, and Rutten, 1993, p. 9). Furthermore, the financing and organization of the health sector affect equity; only by adopting appropriate redistributive mechanisms can the system guarantee affordable health services. Finally, the improper arrangements within the health care system can not only increase the health inequalities, they can also deepen the income inequalities and even bring people to poverty. Therefore, studying the equity issues during the transition of a country is crucial, not only to the success of restructuring health care, which aims to develop an equitable system, but also to the transition process as a whole.

\section{RESEARCH GoALS}

There are many ways to approach the equity theory. It is not a clear ethical concept. The equality of one variable can often clash with the equality of another. Sen (2003) explains this clash with the actual diversity of the human beings and the diversity of focus. To solve these problems he rephrases the search for equality on a practical level to one question: "Equality of what?" To answer this question this research will use the egalitarian definition of the equity of health care provision implied by the Bulgarian Constitution: distribution according to the need and financing according to the ability to pay (Gillon, 1986; Van Doorslaer, Wagstaff, and Rutten, 1993). This study will focus on the ability of the reformed health care system to address the equity in the health care financing challenge during the transition phase (1995-2001).

Equity and health inequalities have been a major focus of research in the Organization of Economic Cooperation and Development (OECD) and developing countries. The existing research on Bulgaria shows an increase in the inequalities regarding the access to health care at the end of the 1980s (Minev, Dermendjieva, and Mileva, 1990). The most recent research examines the problems of informal payments (Delcheva, Balabanova, and McKee, 1997), public attitudes toward payments for health services (Pavlova, Groot, and Merode, 2002), and spatial and temporal access (Balabanova and McKee, 2002b; Pavlova, Groot, and Merode, 2003) during the pre-reform period. The data reveal deepening equity problems in the health care provision in Bulgaria; however, there remains a paucity of evidence regarding the ability of the current health care reform and health care insurance to address these issues. Therefore, this research examines:

Who is paying for health care? How has this changed during the transition period? Are those who need health care able to receive it? If not, why? How has this changed during the transition period? 
In addition to looking at equity in provision of health care, the study examines how the new health care financing arrangements influence income distribution.

The study examines the above questions by looking at several aspects of health care financing. First, it examines the structure of different types of health care financing and its change during the reform. Second, it explores the relationship between income and health care expense. Third, it separates the financial and social reasons for differences in health expenditure by dividing them into economic and social inequity in health care financing. Fourth, it looks at those social factors which shape health expenditure patterns and determines those social characteristics which lead to exclusion from the health care system. Finally, the research examines changes in health care utilization in relation to need and income distribution.

\section{Data Sources AND Methodology}

The research makes use of the Living Standards Measurement Surveys (LSMS) of the World Bank, which are household surveys for the years 1995 and 2001. The aim of the research is to compare the equity of the pre-reform and the post-reform health care provision. The surveys use standardized questionnaires including questions for self-assessed morbidity, socioeconomic status, health care utilization, and expenditure. These are available on a household and personal level, encompassing 2,400 households, or about 7,000 people.

Additional data was obtained from the Bulgarian National Health Insurance Fund, Health Information Center, National Institute of Statistics, and the Institute for Trade Union and Social Research in Bulgaria (ITUSRB) regarding the distribution of resources, diseases, and general health care accounts. Research aims to investigate the different determinants affecting the dimensions of population health so that factors which are specific to the transition period can be identified.

There are two main directions of the analyses: measuring equity in financing, and measuring equity in benefits. Inequalities are investigated on both a "vertical" level—if unequal need or ability to pay is treated with according inequality, and on a "horizontal" level—if equal need or ability to pay are treated equally (Van Doorslaer, Wagstaff, and Rutten, 1993). Therefore, the analyses combine mechanisms measuring health differences between population groups and health distribution across individuals (Anand and others, 2001). The study investigates "relative" as well as "absolute" measures and assesses the difference between the groups with the lowest and highest socioeconomic status as well as the effect on the whole population (Machenbach and Kunst, 1997, pp. 758-759).

\section{A. Health Care Expenses and Income Distribution}

An inequality measure is usually defined in terms of deviation of a given distribution of a variable from the "ideal distribution." The equity measures represent deviation from perfect equality, which in our case is an egalitarian distribution. This comes from the presumption that each individual has an identical utility function with diminishing marginal utility (Kakwani, 1980). According to the chosen definition of equity, our research question could 
be translated into estimation terms as defining if the health care payments are distributed proportionately to the income.

The Gini coefficient attempts to measure the deviation from the perfect equality without regard to the actual function. Mahalnobis (1960) extends and generalizes the concept of the Lorenz curve into the so-called concentration curves. Kakwani (1977a) examines the distribution of different economic variables and gives a more detailed explanation of the concentration curves. Concentration index of a commodity is closely related to its elasticity with regard to the income. Kakwani brings the idea of comparing the elasticity of the different goods by plotting their concentration curves with the Lorenz curve. This gives the opportunity of comparing the distribution of the expenditure for certain goods to the distribution of the income. By means of these concentration indexes Kakwani (1977a) introduces an index of the elasticity (inelasticity) of a commodity. This index indicates the extent to which elasticity deviates from unity over the whole income range.

The concentration curves, first used in health research by Wagstaff and Van Doorslaer (1989) are a standard measure of equity and inequality in health and health care (Koolman and Van Doorslaer, 2004). Therefore, for the purposes of this research, plotting the concentration curve of health care expenses will help in comparing their distribution with that of income. "The concentration curve, and related concentration index, provides a means of assessing the degree of income-related inequality in the distribution of a health variable" (World Bank, 2004a, 2004b). ${ }^{3}$ The concentration index $(C)$ measures the area between the diagonal (or the line of perfect equality) and the concentration curve - F(h) (Kakwani, 1977b, 1980; Kakwani, Wagstaff, and Van Doorslaer, 1997; Wagstaff, Van Doorslaer, and Paci, 1989):

$$
C=1-2 \int_{0}^{1} F(h) d h .
$$

$C$ can take values between -1 and 1 . If $C$ equals " -1 " then all of the observed variable is concentrated in the poorest person. If $C$ equals " 1 " then all of the observed variable is concentrated in the richest person. When $C$ equals " 0 " then the observed variable is distributed on average equally across income. Nevertheless, a " 0 " value for $C$ does not mean that everybody in the society possesses equal portion.

Furthermore, Kakwani (1977b) offers a method of assessing the deviation of the distribution of the commodity from the income distribution. This is the so-called Kakwani index of progressivity $(K)$, which equals the concentration index minus the Gini coefficient $(G)$ (Kakwani, 1977b, 1980; Wagstaff and others, 1999). K is defined as:

$$
K=C-G
$$

$K$ equals twice the area between the Lorenz and concentration curves. If the system is regressive then $K$ is negative, and if the system is progressive then $K$ is positive. $K$ can take

\footnotetext{
${ }^{3}$ A series of 20 Technical Notes includes elaborate description of the quantitative methods for the analysis of health sector inequalities; they were edited by A. Wagstaff, O. O’Donnell, E. Van Doorslaer, and M. Lindelöw, and were published by the World Bank in 2004.
} 
values between -2 and 1 . When $K=-2$ then the income is concentrated in the richest person and the poorest person pays all of the income tax. When $K=1$ then the pre-tax income is distributed equally and the entire tax burden is borne by the richest person. If $K=0$ then there is, on average, proportionate taxation (Wagstaff and others, 1999).

One of the problems with the Kakwani coefficient is that it is very sensitive to the measurement of the Gini coefficient. As health care expenses are a necessity rather than a luxury (Kakwani, 1980), then there are two main factors to determine the Kakwani coefficient. The first is income inequality and the second is the ability of the health system to provide health care according to the ability to pay. Nevertheless, a failure in the system to provide equitable financing for health care will result in relatively worse health equity if there is higher income inequality. In other words, the income inequality factor plays a very significant role in maintaining equitable health care financing. The way in which health care should be financed should be able to respond to the needs of the society and the general economic state in order to maintain a healthy society.

\section{B. Income, Gini Coefficients, and Equivalency Scale}

Considering the importance of the proper choice of an income variable, the study examines the different options. Gini coefficients based on the income of the LSMS surveys give significantly different results from the official statistics for Bulgaria. The main reasons for the differences are the use of income (instead of consumption) as the base for the estimation of the Gini coefficients, differences in the equivalence scales, unit in the surveys (household or person), and the way in which the income variable has been constructed.

The Inequality Database of the United Nations offers a comparison of the Gini coefficients published officially by different national and international organizations (United Nations, 2005). The Gini coefficients vary within significantly broad intervals. The interval for 1995 is between 0.283 and 0.3896 . In 2001, it varies between 0.3215 and 0.5396 . Several conclusions can be drawn from this data. First, the income-based Gini coefficients are significantly higher than the consumption/expenditure based coefficients. As this study is interested in the people's ability to pay, it looks at the income variable which gives more inflated results. These differences might be a result of smaller changes in consumption patterns than in income during the observed period. Second, the discrepancies in 1995 and 2001 between the income and consumption-based income differences grow significantly. The interval rises from 0.106 to 0.216. The Bulgarian National Statistics Institute reports Gini coefficients of 0.36 for 1995 and 0.317 for 2001, which rises slightly to 0.34 for 2002 (National Statistical Institute, 2004). These results are relatively low and do not appear to show social changes, most likely because they are based on consumption variables.

For the purpose of this research the income variable is based on a gross, per capita income equalized with an equivalency scale constructed on the base of the per capita consumption of the households in Bulgaria. The equivalency scale is estimated on the quarterly observations of the consumption patterns in Bulgaria by age group by the ITUSRB, which publishes the only official poverty line and minimum living standard estimates (2004). 
The scale is developed from the quarterly data for the monthly expenses of a four-member family and a single person by age. The values estimated by the ITUSRB are for the period December 2003-December 2004, and are based on monthly household diaries, which give average monthly consumption, by person, by age (Ivanova, 2003). There have been constructed two equations presuming that each member added to an existing household "saves" a fixed sum of his income compared to his expense if he was single. According to age people have different expenses given by the estimated age-price baskets. The average percentage of the cost of living for the above years by age multiplied by the number of people by age in the LSMS data should equal the average in the society estimated by ITUSRB multiplied by the total number of people in the LSMS. The ITUSRB data provide an average cost of living for a working person. This yields the following equations:

$$
\begin{aligned}
& X+(X-s)=2 * C w \\
& (C 3-s) * N 3+(C 6-s) * N 6+(C 13-s) * N 13+(C 18-s) * N 18+X * N 1+(X-s) * N 2= \\
& C a * N a
\end{aligned}
$$

$X$ is cost of living for the head of a family; $s$ is saving from living in an existing household; $C w$ is cost of living of a working person; $N 1$ is number of heads of the families in the dataset; $\mathrm{N} 2$ is number of grownups who are not heads of families in the dataset; $\mathrm{Nm}$ is number of members in the age group where $m$ is the highest age in the group; $\mathrm{Cm}$ is average cost of living by age; $\mathrm{Ca}$ is average cost of living; $\mathrm{Na}$ is total number of people in the sample

The solution of these equations gives the following relations between the family members:

Table 1. Equivalency Scale

\begin{tabular}{|l|l|l|l|l|l|}
\hline $\begin{array}{l}\text { Head of a } \\
\text { family }\end{array}$ & $\begin{array}{l}\text { Adult in the } \\
\text { family }\end{array}$ & Child 0-3 & Child 4-6 & Child 7-13 & Child 14-18 \\
\hline 1 & 0.88 & 0.36 & 0.39 & 0.61 & 0.69 \\
\hline
\end{tabular}

This equivalency scale is based on the consumption patterns in Bulgarian society during the transition period and considers the price relations in the country. Although the consumption baskets are from a period which does not include the years of the LSMS surveys, it is believed to be much closer to the consumption patterns from the surveyed years than the one presumed in general equivalency scales such as the OECD scale.

\section{Standardization}

Existing inequalities in health care financing may be due to differences in the ability of the individuals to pay, or due to differences in the way the system treats individuals with different social characteristics. Therefore, there can be distinction between income-based inequalities and social-status-related ones. The method of standardization for income group helps us distinguish between inequalities in the health care financing due to unequal 
treatment on economic grounds - unequal ability to pay or economic inequalities, and inequalities based on differences in the social status. Kakwani uses this method to exclude from the analysis of health inequalities the unavoidable (policy-irrelevant) inequality, or the one that does not depend on the health care system arrangements (Kakwani, Wagstaff, and Doorslaer, 1997). In terms of health care financing, the standardization method provides a measure of the social and the economic inequality.

Methods of direct and indirect standardization may be used. ${ }^{4}$ The standardized health care expense variable $(y)$ is the difference between observed and expected values of $y(5)$. The expected $y$ for the $i-$ th person is the average $y$ for the individuals with the same standardizing variables as $i$ (Gravelle, 2003). The aim of the standardization is to see the distribution of the variable of interest $y$ in the absence of differences in the distribution of certain standardizing variables $(x)$. The regression equation is thus:

$$
y_{i}=\alpha+\sum_{j} \beta_{j} X_{j i}+\sum_{k} \gamma_{k} Z k i+\varepsilon i
$$

$i$ denotes the individual and $z$ are variables that are not standardized, but which are controlled for in the estimation of $\beta$. The standardized distribution of $y$ is the distribution that can be expected to be observed if there were no differences in the $x$ 's (World Bank, 2004c; 2004e).

If $C$ is the nonstandardized concentration coefficient and $C 1$ is the standardized concentration coefficient, which measures socially-related inequalities in health care, then the economic inequality in the financing of health care is:

$$
\Delta C=C-C 1
$$

In the case of health care expenses the index has a reverse meaning from the original index as it measures expenses ranked by income not utilization (Kakwani, Wagstaff, and Doorslaer, 1997). $\Delta C$ has negative/positive values if economic inequalities are favoring the more/less advantaged members of the society.

$\triangle C$ shows the progressiveness/regressiveness of the health care payments only due to health care financing arrangements. The difference between the Gini coefficient and $\triangle C$ is then a measure of the economic equity $(E e)$.

$$
E e=G-\Delta C
$$

Ee measures the arrangements of the system providing financing according to the individual ability to pay. If Ee is positive/negative, this will mean that the financing of the health care system is progressive/regressive. If $E e$ is equal to 0 then the financing of the health care is on average equitable.

\footnotetext{
${ }^{4}$ The greatest disadvantage of direct standardization is that it can only be used with grouped data and if used with individual data loses the precision from the grouping process (Gravelle, 2003; Kakwani, Wagstaff, and Doorslaer, 1997; Wagstaff and Van Doorslaer, 1998).
} 


\section{Decomposition Analysis}

Standardization assists in estimation of economic inequalities. Still, the inequalities between different social groups are associated with various social arrangements. Each aspect of the socioeconomic status of an individual can have different effects on the health and healthcare-related inequalities. Therefore, the next step will be to study these effects by decomposing the inequality measure by studying the effect of the different socioeconomic groups. The decomposition analysis reveals the relative contribution of these various factors in explaining the total inequality. The inequalities are country specific and the health sector outcomes can vary according to the ability of the system to target the country-specific inequality driving factors. The decomposition health inequality analysis has been used mainly in the analysis of the health inequalities (Claeson and others, 2002;; Van Doorslaer, 2003; Van Doorslaer and Koolman, 2004b; Wagstaff and Van Doorslaer, 2003a; World Bank, 2004c) and service utilization (Van Doorslaer and Koolman, 2004c; World Bank, 2004e). This analysis also contributes to the understanding of equity in the health care financing by mapping the disadvantaged and potentially excluded groups. This model provides the basis for the distribution of targeted subsidies and increases in the equity of health care financing.

The method of standardization uses the concentration index $C$ as a measure of relative income-related inequality. $C$ can be computed using the covariance between $y_{i}$ (health care expenditures or service utilization) and the relative fractional rank $\left(r_{i}\right)$ such that:

$$
C=2 / \bar{y} * \operatorname{cov}_{w}\left(y_{i}, r_{i}\right)
$$

Where $\bar{y}$ is the (weighted) mean of $y$ and wi is the sampling weight if each individual $i$.

Wagstaff, Doorslaer, and Watanabe (2003a) use (5) to decompose the measured degree of inequality into the contribution of the explanatory variables. The $x$ variables are a set of regressors associated with the independent variable. They are exogenous variables that effect the $y$ variable. Therefore, the concentration index can be rewritten as:

$$
C 1=\sum_{k}\left(\beta_{k} * \bar{x}_{k} / \bar{y}\right) C_{k}+C_{\varepsilon} / \bar{y}
$$

$\bar{x}_{k}$ is the mean of $x \boldsymbol{k}$ and $C_{\varepsilon}$ is the generalized concentration index for $\varepsilon i$. The concentration index $C 1$ then consists of the weighted sum of the concentration indices of the $k$ regressors and the residual component. The "shares" of the regressors are the elasticity of $y$ to $x \boldsymbol{k}$. The residual component is the inequality that cannot be explained by the variation of the explanatory $x$ variables. Thus, the total inequality is divided into the inequalities added by each group of $x \boldsymbol{k}$. The decomposition allows for seeing the contribution of each separate regressor by its impact on the demand/need, measured by the elasticity and the degree of unequal distribution across income measured by the $C_{k}$ (Van Doorslaer and Jones, 2004a).

Van Doorslaer and A.M. Jones (2004a) point out that the method has some disadvantages concerning the definition of the policy relevancy of variables. Van Doorslaer, Koolman, and 
Puffer (2002) and Schokkaertm and Van de Voorde (2004) note that the inclusion of the nonneed or policy-based variables can add to the model. Gravelle (2003) develops a model of "partial concentration index" which controls for income and other nonstandardizing policyrelated variables. Thus, he defines three types of $x$ variables $x$ : income $(x i)$, policy-relevant $\left(x_{p}\right)$ and policy-irrelevant variables $\left(x_{n}\right)$. The index is a measure of the "policy-relevant income related inequality" (p. 804). It is estimated by removing the effect of the policyirrelevant or standardizing variables. Gravelle defines as policy-irrelevant variables those, whose effect on $y$ or whose joint distribution with income cannot be altered by policy (p. 804). Then the concentration index equals:

$$
C 2=\left(\beta \imath * \bar{x}_{i} / \bar{y}\right) C_{i}+\sum_{p}\left(\beta_{p} * \bar{x}_{p} / \bar{y}\right) C_{p}+\sum_{n}\left(\beta_{n} * \bar{x}_{n} / \bar{y}\right) C_{n}+C_{\varepsilon} / \bar{y}
$$

The first term is the partial contribution of the income to the inequality ( $C_{i}$ is the Gini coefficient), the second is the contribution of the policy-irrelevant variables, the third is the contribution of the policy-relevant variables, and the last term is the residual term which presents the correlation between the residual and the income rank.

The decomposition offers an alternative estimate of horizontal equity, which in the case of income standardization can be also referred to as economic inequality (6):

$$
E e 1=C-\sum_{n}\left(\beta_{n} * \bar{x}_{n} / \bar{y}\right) C_{n}=\left(\beta_{i} * \bar{x}_{i} / \bar{y}\right) C_{i}+\sum_{p}\left(\beta_{p} * \bar{x}_{p} / \bar{y}\right) C_{p}+C_{\varepsilon} / \bar{y}
$$

Ee1 is the "augmented partial concentration index" used by Gravelle (2003) to estimate the horizontal equity. It estimates the policy-relevant measure of income-related inequality. In the case of health inequalities it excludes from the nonstandardized concentration coefficient the need based (policy-irrelevant) inequalities. In the case of health care financing inequalities it excludes the social inequalities. The residual term is the difference between the actual and the standardized concentration index. There is a debate in the literature if the residual term should be included in the policy-relevant or need-based category (justifiable or unjustifiable inequality). In the original index developed by Gravelle this term is excluded, which supposes that those variables which are not included in the equation are need based and therefore provide need based inequalities. In contrast Van Doorslaer, Koolman, and Jones (2004c) suppose that the inequality unexplained by the standardized equation is a result of the policy-relevant factors. Considering the possible data limitations, this research will treat the inequality expressed by the residual term as unjustifiable and will include it in the policy-relevant income inequality.

Gravelle's index is defined as the directly standardized C (Van Doorslaer, Koolman, and Jones, 2004c). It employs the regression equation to estimate the elasticity of the separate factors. Therefore, when excluding the effect of the $X$ variables the method only extracts the effect of the variables, which are compared to the omitted dummy variables in the equation, because it does not estimate their effect. Furthermore, the economic (policy relevant) inequality expressed by the index depends on the choice of a base income group (need) variable. The standardized $C$ excludes the complete effect of all standardizing variables. Therefore, it is a better measure of the economic inequality. Nevertheless, the method gives a 
way of decomposing $C 1$ and viewing the effects of the separate social factors and their contribution to the general inequality.

\section{E. Benefit Incidence Analysis}

The analysis methods described so far help to explain the inequality distribution of the financing of the health care but they do not facilitate an understanding of who actually receives the benefits from these payments or who uses the health care funds. Equity as an objective of the health care system can be reached by developing target groups and subsidizing different areas. The recipients of these subsidies are not always the target groups. Benefit incidence analysis helps to assess the targeted efficiency of the public subsidies. It also reveals the equity in distribution of health care delivery-if people with equal need are treated equally. Benefit incidence analysis describes the distribution of health sector subsidies across individuals ranked by income (World Bank, 2004d). This distribution shows if the subsidies benefit the poor and close or increase the inequality gap.

Average unit costs are used to estimate the amount of the subsidy. The subsidy received by each individual for each service is equal to the number of times using the service multiplied by the unit cost.

The analysis of proportionality of health care payments gives the redistributive effect of the health care "taxation and payments." Benefit incidence analysis gives the second dimension of influence of health policy on income inequality. It shows the redistributive effect of the health care subsidies and their effect on the way people benefit from the health care system. The above estimates show how the arrangements in the health care system financing and delivery influence the ability of the individuals to receive affordable health care. Nevertheless, there is a third dimension to the relationship between income distribution and health care payments.

\section{F. Poverty Impact of Health Care Payments}

Health care payments do not only influence the access of the individuals to health care; they also reshape the income distribution. An important measure of poverty is the proportion of people who fall under the poverty line. One of the ways to assess the influence of health care system arrangements on poverty is the headcount of those falling under the poverty line in pre- and post-health care payments income distribution proposed by the World Bank (2004g). If we plot the Jan Pen's "parade of the dwarfs" for pre- and post-health care payments we can see the income gap between the two distributions and proportion of the people living under the poverty line before and after the health care payments. Then, the prepayment headcount ration is the number of people with income $x i$ bellow the poverty line $(P)$ divided by the total number of people $(N)$. If $p i=1$ if $x i<P$ then the average prepayment poverty gap equals:

\footnotetext{
${ }^{5}$ See for instance (Cowell, 1995); Jan Pen's parade is one of the ways of mapping income inequality which plots the individual income ranked by income.
} 


$$
G=1 / N \sum N p_{i}\left(P-\chi_{i}\right)
$$

The normalized average prepayment poverty gap (13) eliminates the difference in the currency or the choice of poverty line and allows for comparisons. It is equal to:

$$
N G=G / P
$$

Another measure proposed by Wagstaff and Van Doorslaer (2003b) is the mean positive poverty gap. It measures the mean poverty gap across the poor, or the mean shortfall of those who are in poverty:

$$
M P G=G / H
$$

The difference between pre- and post-payment estimates shows the effect of the health care payments on the poverty distribution. This difference gives the poverty impact $(P I)$ of health care payments.

Another way of looking at the impact of health care payments is by measuring their intensity. We can do this by estimating the ratio of people spending more than a certain proportion of their income on health care. If people spend a big percentage of their income on health care this can suggest several things. First, the use of health care services has significant influence on the income distribution at the point of its use. Second, the impact of health care spending can have long-term influence on the well being of the individuals. Third, the use of health care services may appear to be a major trade off between poverty and better health care status. Furthermore, the distribution of the ratio of health care spending from income between the rich and the poor can be an indicator for the protective mechanisms of the health care system and its ability to provide equitable health care.

Similarly to the head count ratio of people who fall under the poverty line can be estimated the ratio of people who spend more than a certain percentage of their income on health care.

$$
H=1 / N \sum N p_{i}
$$

Where $H$ is the headcount and $p_{i}$ is the number of people who spend more than $X$ percent of their income on health care. $X$ can vary according to the analysis and the given data. Additionally, for proportion of the spending on health care can be estimated the average gap (12) and the normalized gap (13) (World Bank, 2004f).

These indicators do not give any information about the distribution of the health spending ratio between the rich and the poor. Wagstaff and Van Doorslaer (2003b) suggest the use of concentration indexes. They propose using two concentration indexes. The first $(\mathrm{Ch})$, measuring the location of the incidence, estimates the distribution of people who spend a big proportion of their income on health care among the rich and the poor. The index is defined in reference to a concentration curve plotting the cumulative proportion of the population against the cumulative share of the people exceeding the threshold. The other index $(C O)$ is 
measuring the intensity of impact amongst the income distribution, assessing the overshoot. This index is defined in reference to a concentration curve plotting the cumulative proportion of the population against the cumulative share of the overshoot over the threshold. A positive value for Ch suggests that the better-off are more likely to exceed the threshold, and a negative value indicates that the worse-off exceed the threshold more often. Seemingly, a positive value of $C O$ means that the better-off are spending a larger proportion of their income on health care over the threshold and a negative value indicates that the worse-off are more likely to do so. Although the concentration index catches the effect of economic position of the individuals and the head count and the gap show the size of the health care burden, none of these measures gives us the whole effect of the health care payments and the economic position. Therefore, Wagstaff and Van Doorslaer (2003b) provide a measure including both tendencies. They suggest giving a rank to the people from 1 to $N$. Then, the weight of the most disadvantaged person will be 2 and the weight of the least disadvantaged person will be $2 / \boldsymbol{N} \rightarrow 0$ when $\boldsymbol{N} \rightarrow \infty$. When weights are applied, the weighted coefficient for the head count can be transformed into: ${ }^{6}$

$$
H W=H(1-C H)
$$

The weighted coefficient for the overshoot will be:

$$
G W=G(1-C O)
$$

Therefore, if $C h$ has a positive value then the better-off pay a larger proportion of their income for health care and this may reduce the effect of having more people paying a high proportion of their income for health care and vice versa.

\section{RESUlts}

\section{A. Ill Health and Health Care Expenditure}

Figures 1 and 2 present the health care expenses and the health care need by income quintile and type of health care payment for 1995 and 2001. There does not appear to be a significant correlation between income distribution and the occurrence of ill health or disability for the two years. Nevertheless, out-of-pocket payments constitute the majority of health care expenses. This particularly influences the low-income quintiles when people suffered from illness in 1995. Their out-of-pocket expenses are more than twice as large as the average and are larger than those of the long-term disabled. Therefore, total health care expenses are substantially larger for those who have been ill. For the upper quintiles, the occurrence of disease does not appear to play such a significant role. Long-term disability also shapes the expenditure curves, and there is a positive trend in both out-of-pocket and total payments with the increase of the income. In comparison, the health expenditure distribution in 2001 seems to have a much clearer trend in that there is an increase in spending with an increase in income. This may be influenced by the relatively low number of ill and disabled in the lowest

\footnotetext{
${ }^{6}$ A detailed proof can be found in the Appendix of Wagstaff and Van Doorslaer, $2003 \mathrm{~b}$.
} 
quintile. Still, the occurrence of both risks has significant influence on expenditures, but in comparison to 1995, it seems to have a more substantial impact on the high-income groups.

Figure 1: Health care expenses by type and by quintile, 1995

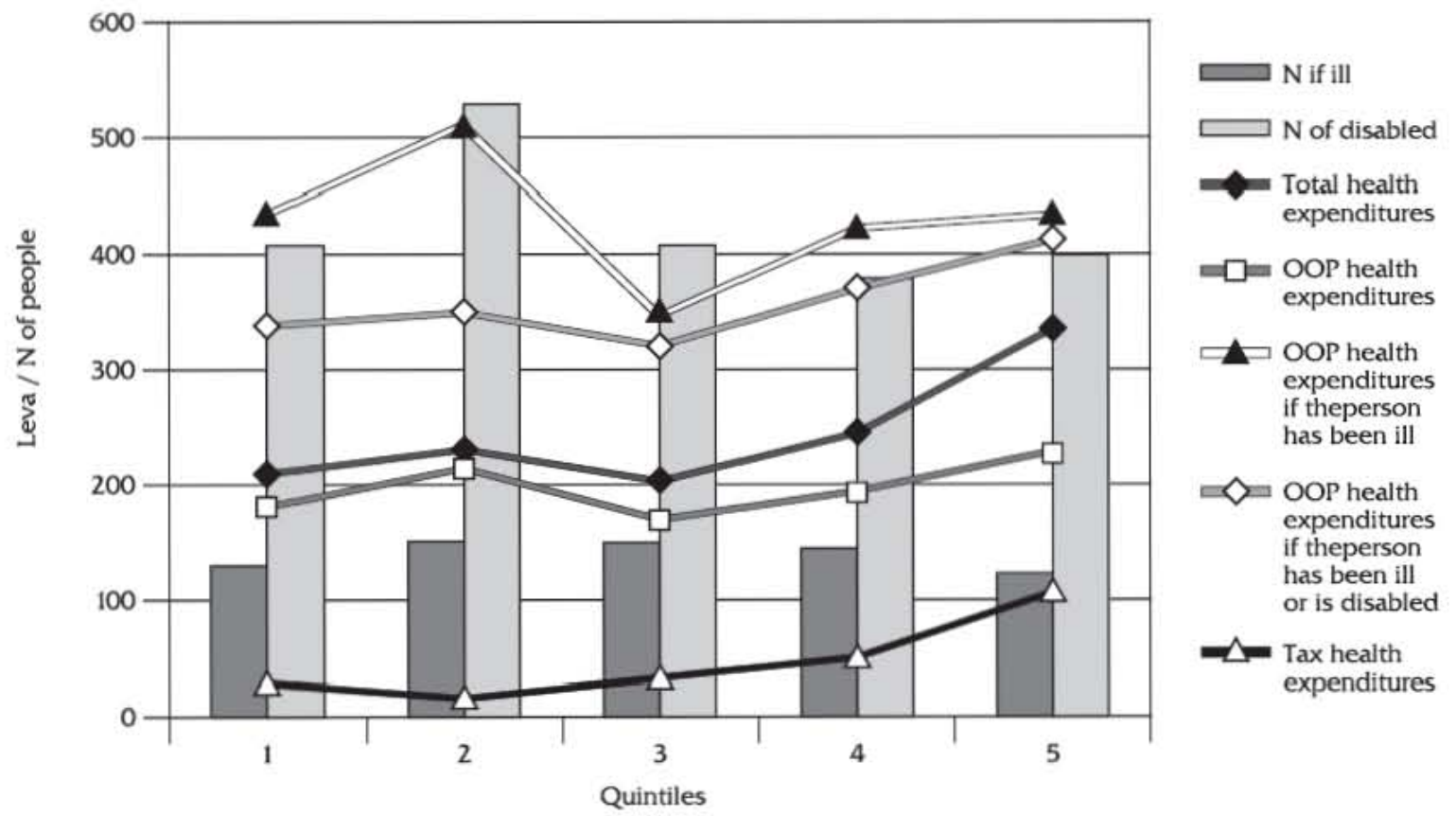

Source: LSMS, Bulgaria 
Figure 2: Health care expenses by type and by quintile, 2001

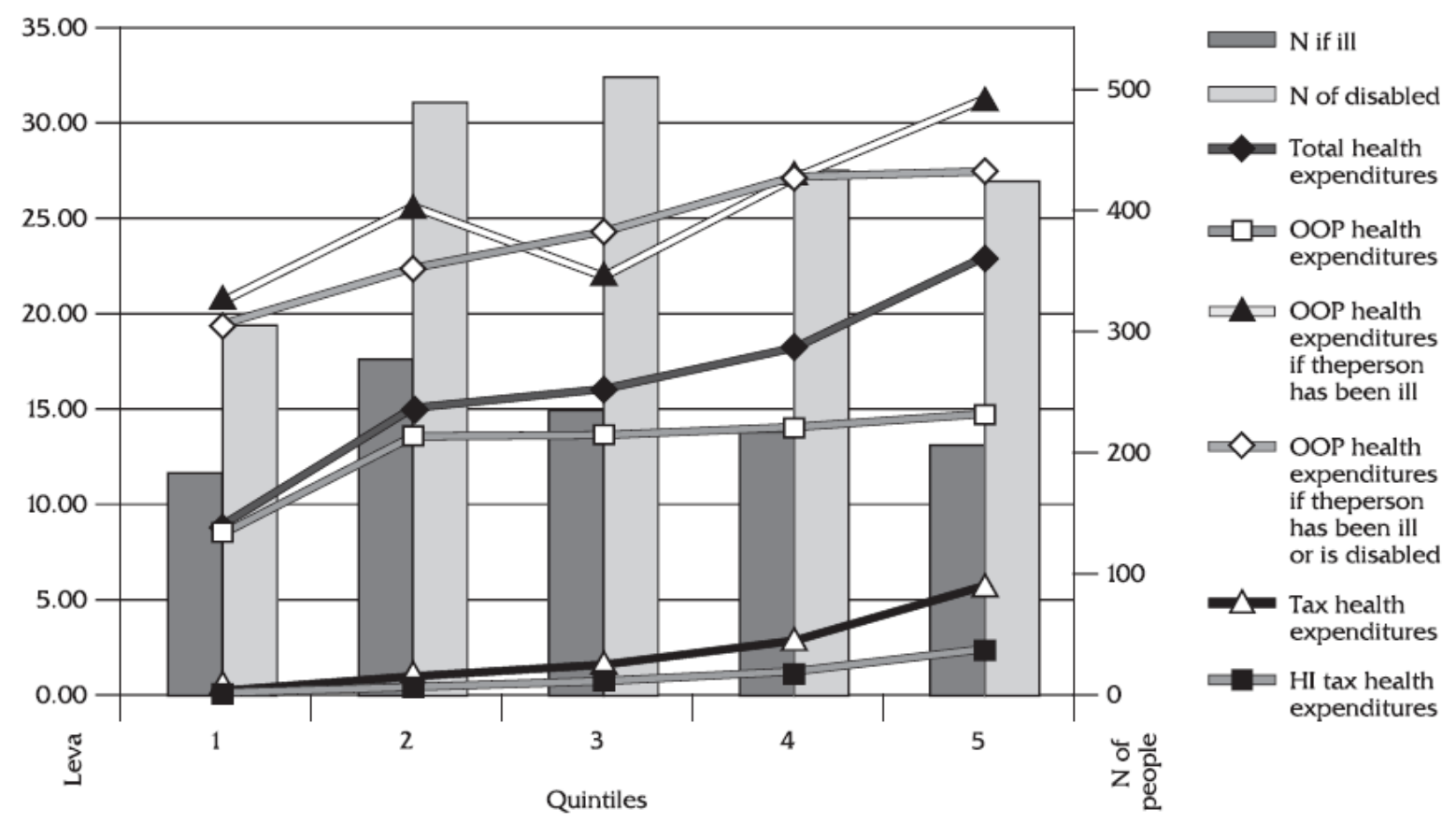

Source: LSMS, Bulgaria

In 2001 the rich were spending more out-of-pocket while needing health care. The positive trend in the total health spending in all groups is additionally shaped by the progressiveness of the health insurance tax and the percentage of general taxes that are spent on health care. ${ }^{7}$ It may be noted that, after the reform, the health insurance contribution and the "tax financed" health expenditures are an insignificant part of the total health expenditures and, therefore, insufficient to change their distribution. Although this gives progressivity to the health care expenditures, the poor have very significant out-of-pocket contributions. The introduction of health insurance does not appear to have changed the problem with large expenses associated with the experience of ill health. Should the poor experience a health risk, it can produce a shock effect on their budgets and create additional social problems.

\section{B. Income Distribution and Health Care Expenditure}

To look more closely at the health expenditures distribution in comparison to the income distribution, the study will examine the Lorenz and the concentration curves for 1995 (Figure 3 ) and 2001 (Figure 4). The curves are a method of visualizing the equity of the different types of health care payments. An equitable distribution will be the one which has a concentration curve coinciding with the Lorenz curve. In this case people will be paying for health care according to their ability to pay (their income). Any curve that lies below the Lorenz curve will have a progressive taxation effect on income, and any curve above it will

\footnotetext{
${ }^{7}$ The tax health expenditures are estimated as a certain percentage of the tax paid. The percentage equals the total government spending on health care of the total tax collected for the year.
} 
have a regressive effect. Thus the areas between the concentration curves and the Lorenz curves can be compared. This comparison can be numerically presented by the Kakwani coefficient-Table 2, (1) and (2). If the curves do not coincide it will be clear which distribution is more progressive/regressive, and if they do coincide, it should be taken into account the marginal utility of the individuals above and below these points. While using concentration and Kakwani Coefficients each individual is given equal marginal utility. In other words, they treat the poorer and the richer person as having equal benefit from any additional unit of income. Therefore, both the curves and the coefficients should be examined.

Table 2. Gini, Concentration, and Kakwani Coefficients

\begin{tabular}{|l|l|l|l|l|l|l|l|l|l|}
\hline Year & $\begin{array}{l}\text { Gini } \\
\text { coefficient }\end{array}$ & \multicolumn{4}{|l|}{ Concentration coefficients } & \multicolumn{4}{l|}{ Kakwani coefficients } \\
\cline { 3 - 9 } & & $\begin{array}{l}\text { Out-of- } \\
\text { pocket } \\
\text { payments }\end{array}$ & $\begin{array}{l}\text { Tax } \\
\text { payments }\end{array}$ & $\begin{array}{l}\text { Health } \\
\text { insurance } \\
\text { payments }\end{array}$ & $\begin{array}{l}\text { Total } \\
\text { health } \\
\text { payments }\end{array}$ & $\begin{array}{l}\text { Out-of- } \\
\text { pocket } \\
\text { payments }\end{array}$ & $\begin{array}{l}\text { Tax } \\
\text { payments }\end{array}$ & $\begin{array}{l}\text { Health } \\
\text { insurance } \\
\text { payments }\end{array}$ & $\begin{array}{l}\text { Total } \\
\text { health } \\
\text { payments }\end{array}$ \\
\hline 1995 & 0.354 & 0.034 & 0.359 & no & 0.096 & -0.320 & 0.005 & no & -0.258 \\
\hline 2001 & 0.468 & 0.072 & 0.466 & 0.443 & 0.152 & -0.396 & -0.002 & -0.025 & -0.316 \\
\hline
\end{tabular}

Source: LSMS, Bulgaria

The only health care payment with a slightly progressive effect on income is the tax payment in 1995. Closer examination of the tax concentration curve for 1995 shows that these payments are very regressive for the upper part of the bottom quintile of the income distribution. Similarly, for the same part of the population there are very regressive trends in out-of-pocket and total health care payments. Therefore, the taxation in 1995 can be considered inequitable for the population between the second and the fourth decile.

In contrast, although the Kakwani coefficients for tax payments and health insurance payments are slightly regressive in 2001, the curves show that they are quite proportionate to the income for the lower-income groups. This in general is more important for the distribution of health care payments because although equitable is considered a payment made according to the ability to pay, the marginal utility of the poor is much higher. 
Figure 3: Lorenz and Concentration Curves, 1995

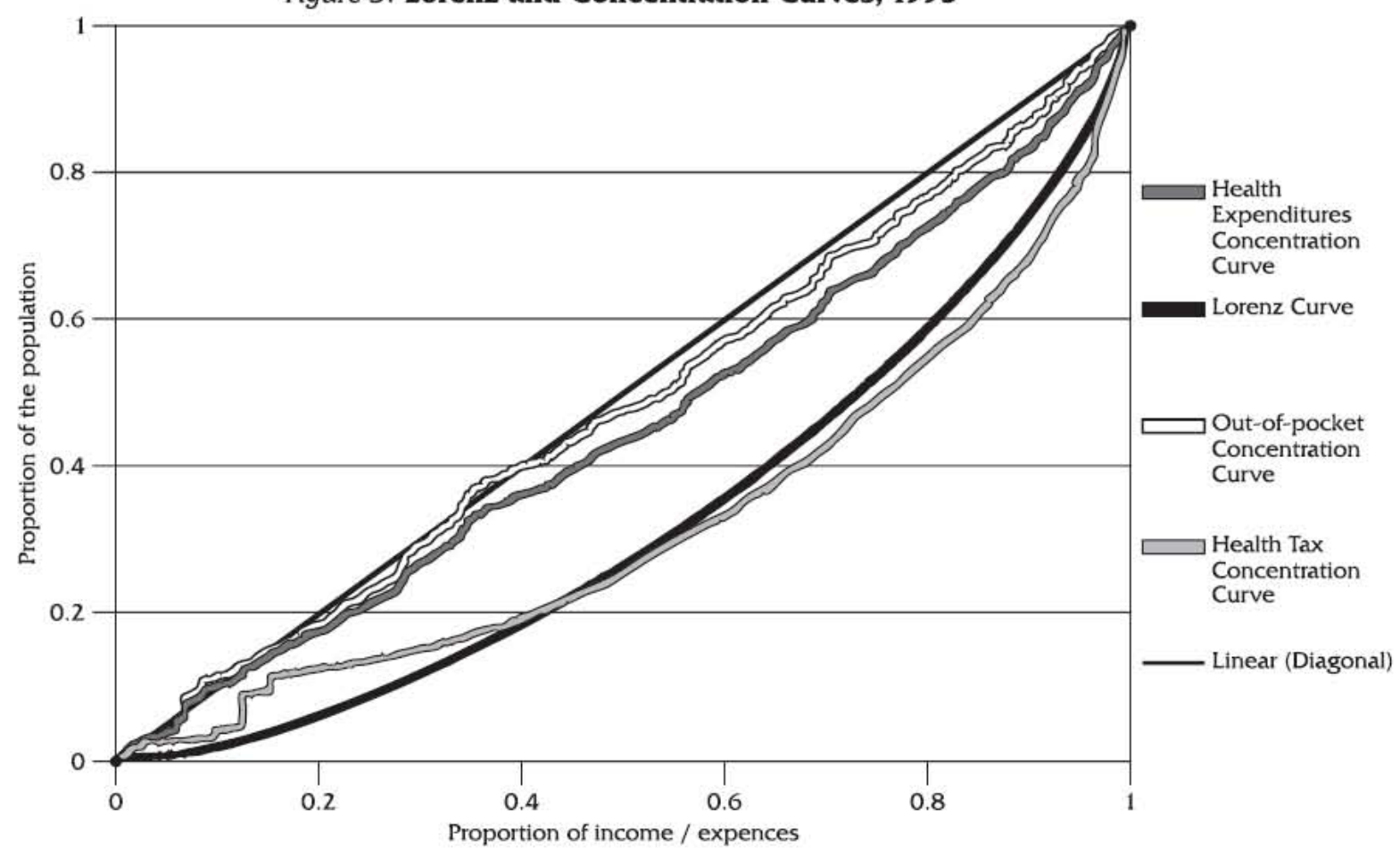

Source: LSMS, Bulgaria

Figure 4: Lorenz and Concentration Curves, 2001

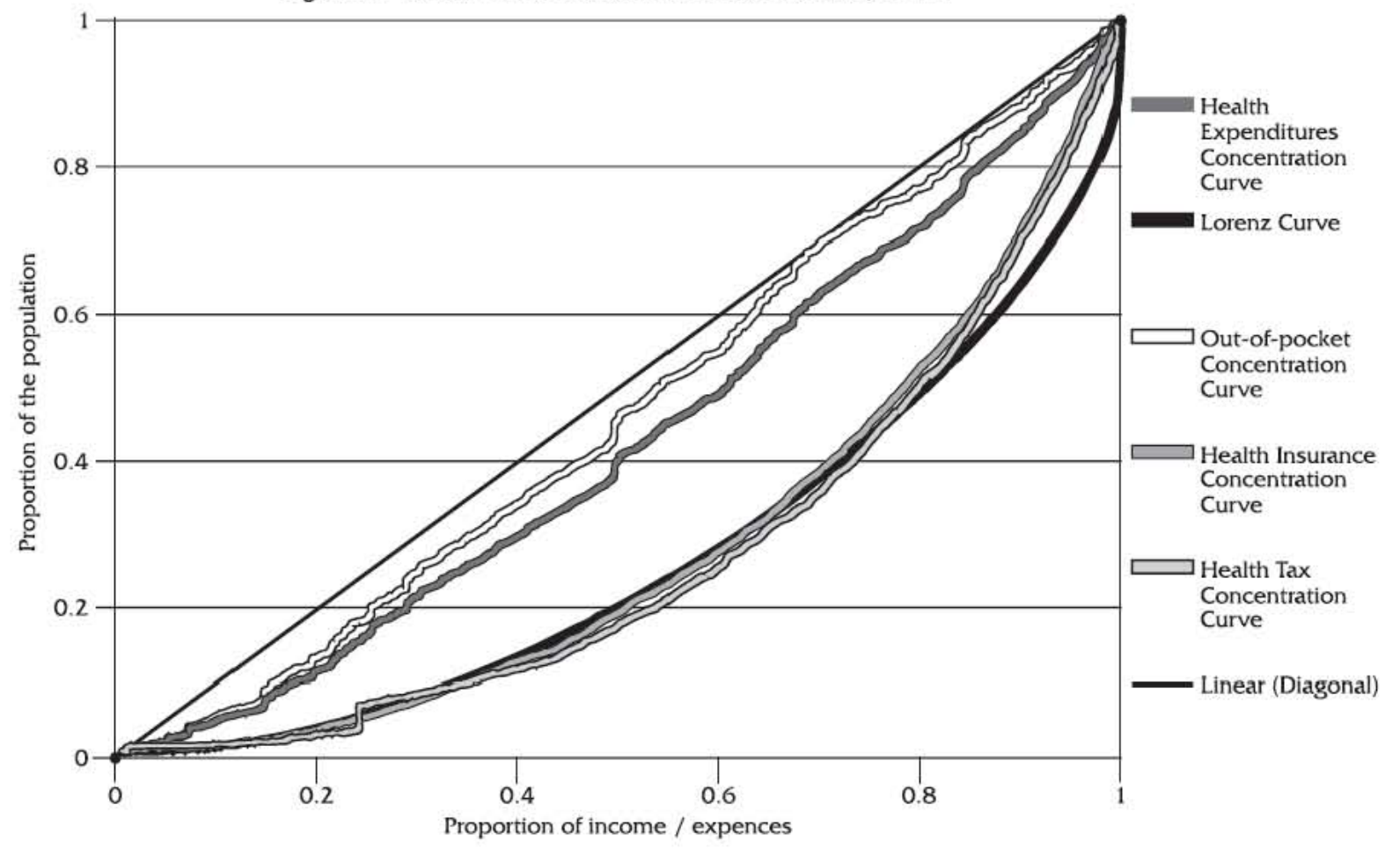

Source: LSMS, Bulgaria 
When considering the proportion of the different methods of health care financing it has to be noted that the structure of the OOP and the tax-financed payments has not changed. In 1995, there was 81 percent financing from OOP and 19 percent through general taxation. In 2001, the financing was 80 percent from OOP, 14 percent through general taxation, and 6 percent from health insurance contributions. These results suggest that the influence of the reforms on the financing of the health care system have a very insignificant effect. Although the reforms may have established equitable financing through health insurance taxation, this has not changed the financing structure of the revenues. Therefore, the reforms have been unable to shift the total financing of the health care sector toward financial-ability-based financing.

These results lead to several conclusions. First, the income inequality has increased very substantially between 1995 to 2001. The Gini coefficient has increased by 24.4 percent. This puts a big challenge in front of the health care system to reach equitable financing. Second, all health care payments are much more progressive to the income in 2001, but considering the steep slope of the Lorenz curve, the system has not developed a mechanism to respond to the changes in the economy. Third, in 2001, there was still a very large percentage of OOP, which as in 1995 was very regressive. This makes the total health payment distribution a very regressive one. Finally, the more negative Kakwani coefficient for the total health payments in 2001, measuring the proportionality of the health care payments to the income, shows a significant increase in the financial equity problem. Nevertheless, if the lower-income groups are considered, from the figures it is visible that the gap between the income and the health care payment in 2001 is much smaller than in 1995. It appears that, although the system has not managed to reach the equity goal, it has made it relatively cheaper for the poor to access the system under the context of an increasing challenge to reach equity.

\section{Economic Financial Equity}

So far the research has only looked at the unstandardized concentration coefficients. If it wants to assess the economic equity, or the distribution of health care expenses amongst the people with different ability to pay, it should estimate the income-related inequalities, which are the $X$ variables (5). For this purpose the sample is divided into 100 income groups. The regression controls for age-sex differences, marital status, nationality, public/private facility use, region, education, and employment status. These are the $Z$ variables in the regression equation (5).

The Newey-West convenient regression method is used to control for serial correlation and heteroscedasticity. The income standardized $C 1$ for 1995 (with control for the $Z$ variables) is 0.0533 with t-ratio: 2.3 and for 2001 is 0.08 with t-ratio: 4.96 and 0.00 significance. This is the social inequality in the health care financing. The difference between $C$ and $C 1$ is the concentration coefficient of income-based inequalities in health care financing.

(1995) $\Delta C=0.0964-0.0533=0.0431$

(2001) $\triangle C=0.1518-0.08=0.0718$

The index (6) is positive (Van Doorslaer, Koolman, and Jones, 2004c). Therefore, the economic inequality favors those who are worse off. There are several conclusions to be made. Both income- and nonincome-related factors contribute to inequalities in financing 
which favor the poor. The distribution of health care expenses became more progressive after the health care reforms due to income-related differences. Furthermore, the increase in C1 shows that the factors unrelated to income have also led to an increase in the progressiveness of the health care payments. Although generally this might appear as a positive tendency, it might be a result of abstention from health care among some social groups. Moreover, the health care policy response to income inequalities is smaller than it can actually reflect upon the population. This response can be seen by the change in the Ee (7) (Table 3).

Table 3. Gini, Income-Driven Concentration, and Economic Equity Coefficients

\begin{tabular}{|c|c|c|c|c|c|}
\hline \multirow[t]{2}{*}{ Year } & \multirow[t]{2}{*}{$\begin{array}{l}\text { Gini } \\
\text { Coefficient }\end{array}$} & \multicolumn{2}{|c|}{$\begin{array}{l}\text { Income-driven Concentration } \\
\text { Coefficients }\end{array}$} & \multicolumn{2}{|c|}{ Economic Equity Coefficients } \\
\hline & & $\begin{array}{l}\text { Out-of-pocket } \\
\text { payments }\end{array}$ & $\begin{array}{l}\text { Total health } \\
\text { payments }\end{array}$ & $\begin{array}{l}\text { Out-of-pocket } \\
\text { payments }\end{array}$ & $\begin{array}{l}\text { Total health } \\
\text { payments }\end{array}$ \\
\hline 1995 & 0.354 & -0.006 & 0.0431 & 0.360 & 0.311 \\
\hline 2001 & 0.468 & 0.004 & 0.0718 & 0.464 & 0.396 \\
\hline
\end{tabular}

Source: LSMS, Bulgaria

Ee reflects only the policy of health care financing. It excludes from the equation factors that have influenced the health care payment distribution which are not related to the income distribution. This measure will exclude the effect of abstaining from use of the health care services for nonincome-related reasons.

The standardized $C$ for the out-of-pocket payments (C1oop) provides results for the incomedriven concentration coefficient which are slightly different.

(1995) $\triangle$ Coop $=0.034-0.04=-0.006$

(2001) $\triangle$ Coop $=0.072-0.068=0.004$

The effect of income driven inequality, as expected, is very small. The negative value of the $\triangle C o o p$ in 1995 means that the out-of-pocket payments are regressive to income in relation only to the income groups. In other words, if all of the other social factors were equal, more out-of-pocket payments would have been paid by the poor. However this trend changes after the reform, due either to regulation, or to financially motivated abstention from the use of health care. Income has a progressive influence on the OOP. Nevertheless, this influence is very small. A further study of the factors that define the level of health care expenses will include decomposing the concentration of the OOP. People's motivation for spending on health care is based on the expenses which they make out-of-pocket. Therefore, OOP will be used for an analysis of the socially determined health care expense patterns.

\section{Influence of the Social Status on the Financial Equity}

Decomposition of the health care inequalities can give a more detailed explanation of the influence of the different social factors on the general inequality in the financing of health care (10). Only 10 percent of the variability of the health care expenses can be explained by 
the controlling factors. Figure 5 and Figure 6 show the contribution of the factors to the concentration coefficient of the health care expenses.

Table 4 shows the elasticity of the OOP health expenses with respect to the studied factors, the concentration index of $Z(\mathrm{Cz})$ in relation to income, and their contribution to $C$. The elasticity shows the corresponding change in health care expenses with the change of the factor. $\mathrm{Cz}$ shows the distribution of people with the studied characteristics amongst the income range. Negative elasticity is often combined with negative concentration indexes, which gives a positive contribution of the factor to $C$. A negative/positive value for $C z$ means that there is a higher concentration of the $Z$ category within the poor/rich. A negative/positive elasticity means that the $\boldsymbol{Z}$ category spends on average less/more of its income on health care.

One of the main contributors to $C$ is the Roma ethnic group, which is on average significantly poorer and has decreasing health care spending. This tendency to an increase in socially related differences in the spending amongst the different nationalities is an example of a growing progressivity of health care spending as a result of growing social inequalities. This demonstrates that the concentration coefficient alone cannot determine the character of the inequalities in the health care payments, namely income proportionality, which we aim at, or social exclusion. Within the Turkish minority group, there is also a negative $\mathrm{Cz}$ and elasticity, presuming abstention from utilization, but this tendency has decreased over time. It is interesting to note that although this group has become poorer, it has started spending more on health care.

Figure 5: Influence of the different factors on the Concentration indexof health OOP, 1995

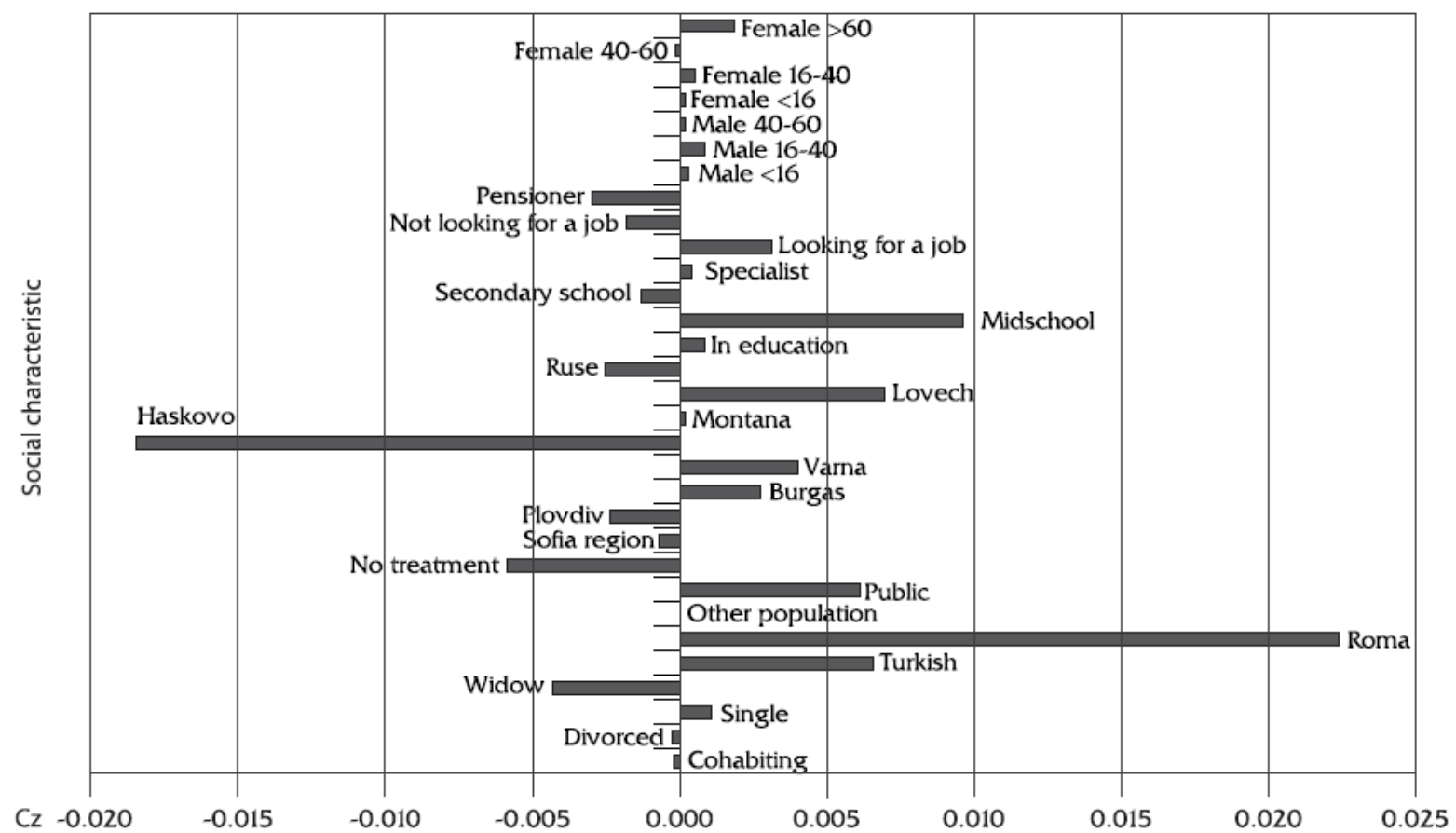

Source: LSMS, Bulgaria 
Figure 6: Influence of the different factors on the Concentration indexof health OOP, 2001

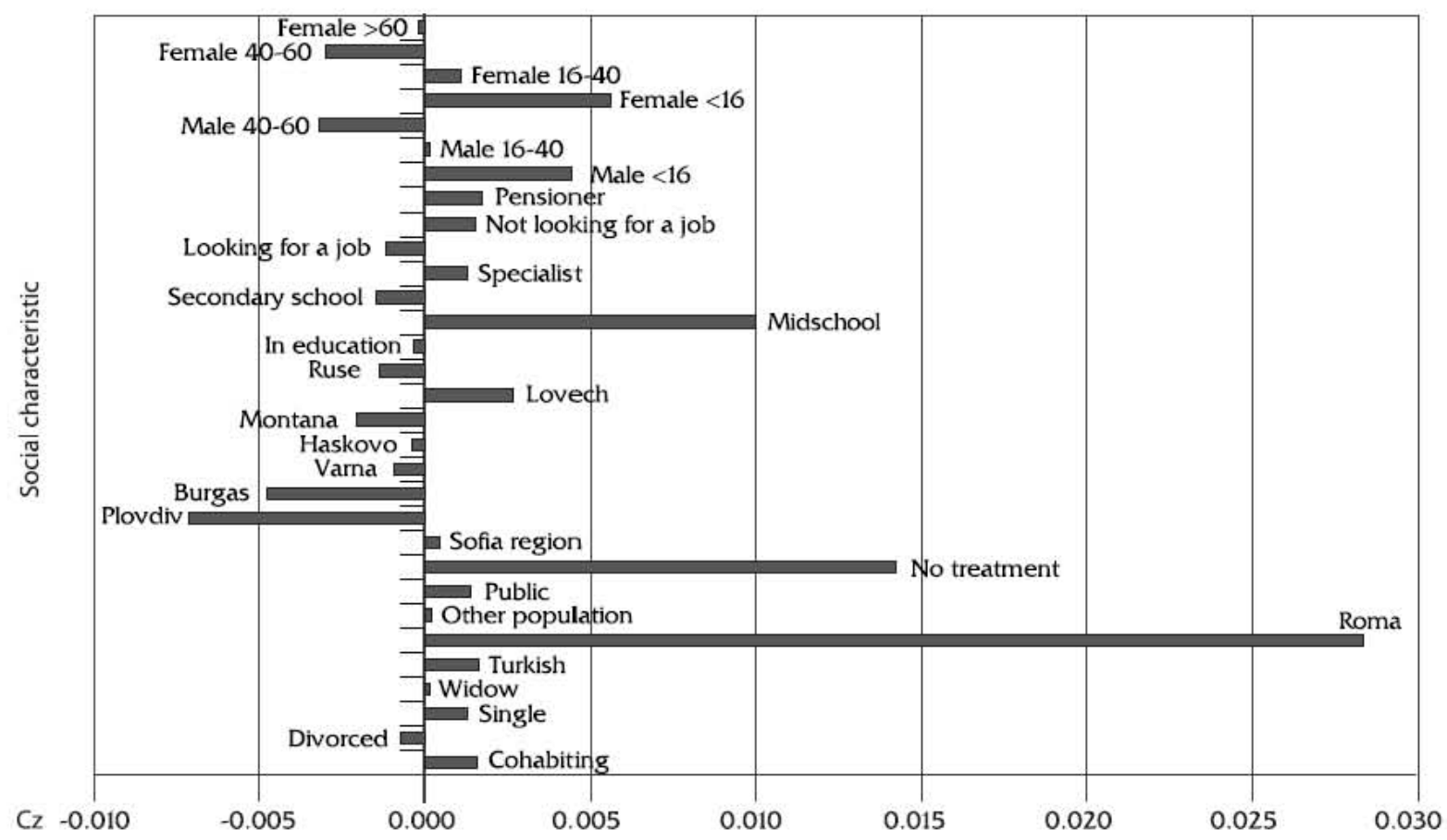

Source: LSMS, Bulgaria 
Table 4. Elasticity, Z Concentration Coefficients, and Their Contribution to C

\begin{tabular}{|c|c|c|c|c|c|c|c|c|}
\hline & \multicolumn{4}{|l|}{1995} & \multicolumn{4}{|l|}{2001} \\
\hline & $\begin{array}{l}\text { Elasti- } \\
\text { city }\end{array}$ & $\mathrm{Cz}$ & $\begin{array}{l}\text { Contri- } \\
\text { bution }\end{array}$ & $\begin{array}{l}\% \\
\text { contrib }\end{array}$ & $\begin{array}{l}\begin{array}{l}\text { Elasti- } \\
\text { city }\end{array} \\
\end{array}$ & $\mathrm{Cz}$ & $\begin{array}{l}\text { Contri- } \\
\text { bution }\end{array}$ & $\begin{array}{l}\% \\
\text { contrib }\end{array}$ \\
\hline Cohabiting & 0.004 & -0.024 & 0.000 & -0.003 & -0.004 & -0.367 & \begin{tabular}{|l|l|}
0.002 \\
\end{tabular} & 0.023 \\
\hline Divorced & 0.002 & -0.0 & 0.000 & -0.0 & & -0.053 & -0.001 & -0.010 \\
\hline Single & -0.054 & -0.020 & 0.001 & 0.0 & 25 & -0.053 & 0.001 & 0.018 \\
\hline Widow & 0.029 & -0.146 & -0.004 & -0.126 & 0.006 & 0.009 & 0.000 & 001 \\
\hline Turkish & -0.046 & -0.141 & 0.006 & 0.190 & -0.005 & -0.315 & 0.002 & \\
\hline Roma & -0.034 & -0.653 & 0.022 & 0.661 & -0.043 & -0.657 & 0.029 & 0.396 \\
\hline Other pc & -0.003 & -0.001 & 0.000 & 0.000 & -0.001 & -0.153 & 0.000 & 0.001 \\
\hline Public & -0.286 & -0.021 & 0.006 & 0.180 & 0.027 & 0.053 & 0.001 & 0.020 \\
\hline No tre & -3.725 & 0.002 & -0.006 & -0.1 & & & 0.014 & 199 \\
\hline Sofic & & 036 & -0. & & & 84 & 000 & 07 \\
\hline Plovd & 033 & -0.075 & -0.0 & -0.1 & & -0.150 & .007 & \\
\hline Burga & -0.042 & -0.064 & 0.003 & 0.07 & 055 & -0.086 & 0.005 & \\
\hline Varna & -0.032 & -0.124 & 0.004 & 0.117 & 0.021 & -0.044 & -0.001 & -0.0 \\
\hline Haskovo & -0.108 & 0.171 & -0.018 & -0.543 & 0.032 & -0.010 & 0.000 & -0.005 \\
\hline Montana & -0.005 & -0.008 & 0.000 & 0.001 & 0.016 & -0.126 & -0.002 & -0.029 \\
\hline Lovech & -0.079 & -0.089 & 0.007 & 08 & 0.039 & 0.069 & 0.003 & \\
\hline Ruse & & & & & 16 & & -0.001 & -0 . \\
\hline $\mathrm{e}$ & & 030 & & & & & 0.000 & \\
\hline Mids & & 0.115 & & & & -0.246 & 0.010 & \\
\hline Seconc & -0.027 & 0.047 & -0.001 & -0.0 & -0.0 & 0.139 & -0.001 & -0.0 \\
\hline Specialist & 003 & .094 & 0.000 & 0.009 & 0.005 & 0.275 & 0.001 & 0.018 \\
\hline Looking for & -0.009 & -0.330 & 0.003 & 0.090 & 0.003 & -0.368 & -0.001 & -0.015 \\
\hline Not looking - job & 0.009 & -0.202 & -0.002 & -0.052 & -0.005 & -0.344 & 0.002 & 0.022 \\
\hline Pensioner & 0.036 & -0.081 & -0.003 & -0.086 & 0.083 & 0.021 & 0.002 & 0.024 \\
\hline Male <16 & -0.003 & -0.077 & 0.000 & & -0.034 & -0.131 & 0.004 & 0.062 \\
\hline Male 16-40 & 0.028 & 0.028 & & & & -0.004 & 0.000 & \\
\hline Male 40-60 & 0.002 & 0.085 & 0.000 & 0.004 & -0.035 & 0.091 & -0.003 & -0.044 \\
\hline Female $<16$ & -0.008 & -0.019 & .000 & & -0.037 & -0.152 & 0.006 & 0.078 \\
\hline & & & & & & -0.024 & 0.001 & 0.015 \\
\hline & & 0.043 & .000 & -0.0 & -0.0 & 0.075 & -0.003 & -0.042 \\
\hline Female $>60$ & -0.015 & -0.115 & 0.002 & 0.052 & -0.012 & 0.006 & 0.000 & -0.001 \\
\hline
\end{tabular}

Source: LSMS, Bulgaria

Likewise, the group with the lowest education has a positive contribution to $C$ due to negative $C z$ and elasticity. Over time there has been a tendency towards a reduction in the economic status of the less educated people but the discrepancies in their health care spending have diminished. 
If we look solely at the relation between the factors and the average spending on health care of the groups, pensioners spend the largest amount on out-of-pocket health care expenses. This suggests that this social group is one of the biggest contributors to health care financing from disposable income. The pensions in Bulgaria are very low but it appears that the majority of pensioners live in households which are not on average much poorer which allows them to cover this expense. Considering the strong family structure of Bulgarian society, this implies that pensioners have to depend on the other members of the household to be able to cover their medical needs.

There are also regional discrepancies which tend to favor the poor in the wealthier regions, but this has had a reverse effect over time. Treatment in a public facility also has a positive effect on $C$. In 1995, the poor were spending more in the public health care sector, and they were spending less on average. In 2001, this trend changed and the rich are making more outof-pocket payments in the public sector. Interestingly, the positive elasticity of the use of the public sector presumes that people who use it pay more than in the private one. This may be an effect of the recent reform and the rise of the corruption and the increase in the use of private services from 4 percent in 1995 to 35 percent in 2001 in the outpatient sector (Table 5). This presumption may be examined by studying service utilization.

\section{E. Health Care Service Utilization and Financial Equity}

The above results suggest that some of the changes in health spending patterns might have been a result of abstention from health care use because of the increase in the burden of health care costs. This hypothesis may be tested by looking at the number of people who have reported that they have not used health care services whilst ill, because it was not affordable. Figure 7 and Figure 8 test this hypothesis. A direct measure of the changes in nonutilization is the percentage of ill persons who did not use health care because they could not afford it. In 1995, there is a slight trend toward nonutilization in the bottom quintiles, but if the actual percentages are taken into account it appears that in 2001 there were more than 65 percent in the poorest quintile that couldn't afford to use health care, versus 21 percent in 1995. The trend of decrease of this percentage is clearer in $2001-9$ percent in the upper quintile and 11 percent in 1995. This reveals a serious problem for financial access to the health care system after the reforms.

The discrepancies in the need and use of health care are examined according to the utilization of the services. ${ }^{8}$ Table 5 shows that in 1995 utilization is mainly dependent on number of consultations, and there is no pro-poor or pro-rich trend. In 2001 there was an increase in utilization for upper-income quintiles connected with the lower use of outpatient care by the lower quintiles. This phenomenon can be explained by nonutilization due to financial restraints. In other words, the lack of financial protection for the poorest people has not only left them without access to the health care system, but has also left them with lower use of public subsidies. Furthermore, it can be concluded that there is a trend toward subsidizing health care for the wealthier segments of the society.

\footnotetext{
${ }^{8}$ The utilization of health care subsidies was estimated on an average price per outpatient visit in 1995 (NCHI and Ministry of Health 1996) and price as defined by the National framework contract for 2001 (National Framework Contract, 2000).
} 
Figure 7: Outpatient utilisation, 1995

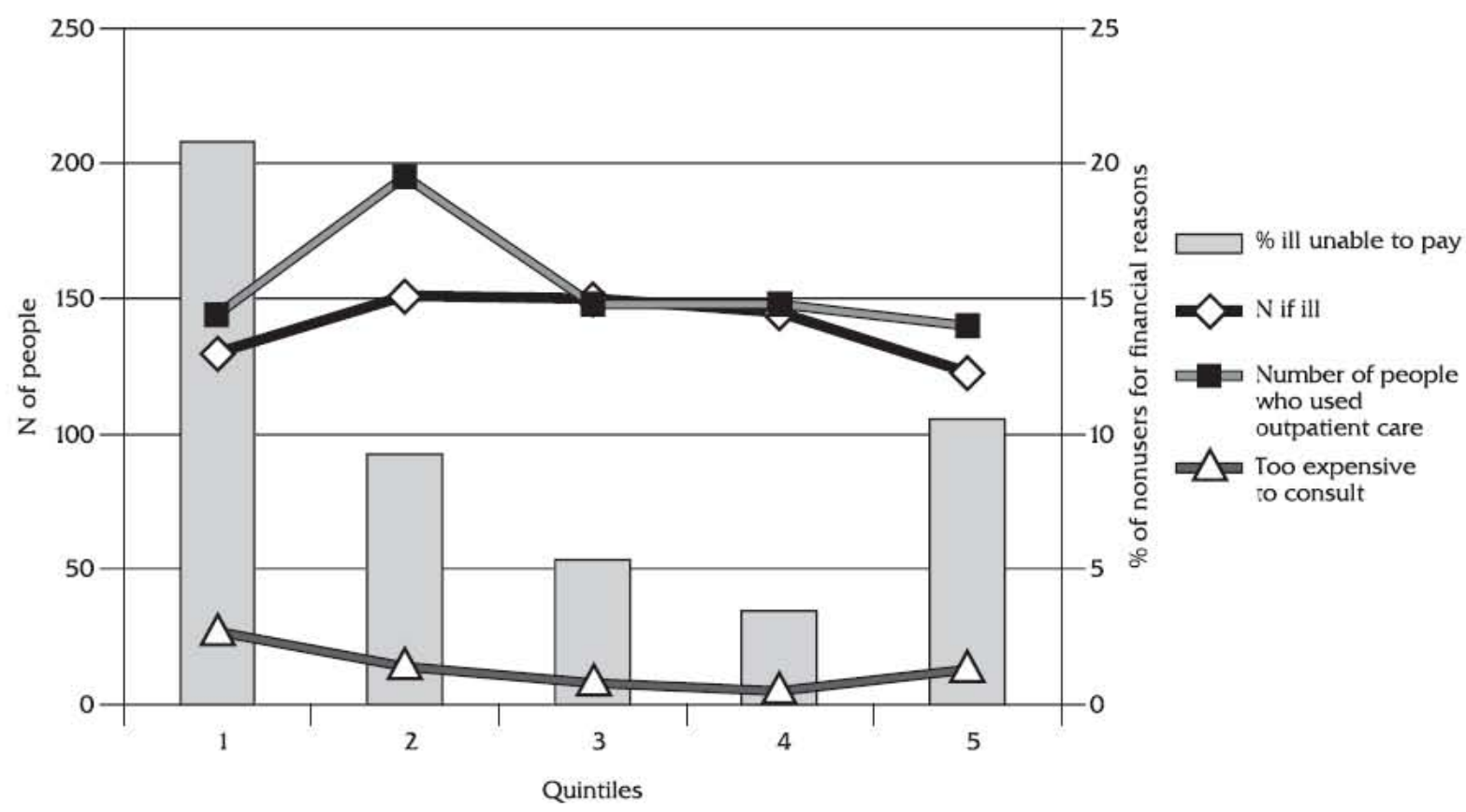

Source: LSMS, Bulgaria

Figure 8: Outpatient utilisation, 2001

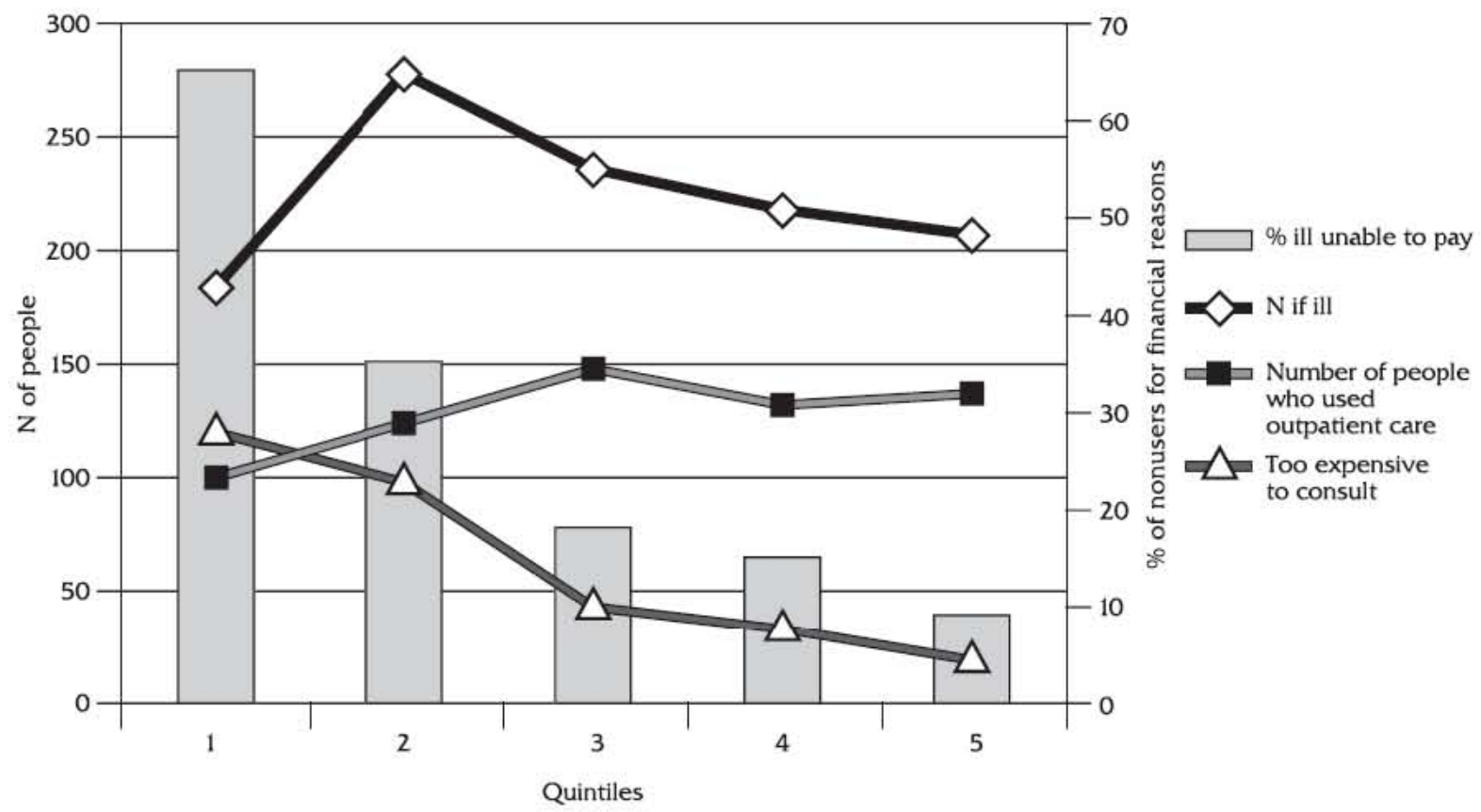

Source: LSMS, Bulgarla 
Table 5. Outpatient Utilization

\begin{tabular}{|c|c|c|c|c|c|c|c|c|c|c|c|c|}
\hline Quintile & \multicolumn{5}{|l|}{1995} & \multicolumn{5}{|l|}{2001} & \multicolumn{2}{|l|}{ Total } \\
\hline Year & Q1 & Q2 & Q3 & Q4 & Q5 & Q1 & Q2 & Q3 & Q4 & Q5 & 1995 & 2001 \\
\hline $\begin{array}{l}\text { Number of } \\
\text { people who used } \\
\text { outpatient care }\end{array}$ & 144 & 195 & 148 & 148 & 140 & 100 & 124 & 148 & 132 & 137 & 775 & 641 \\
\hline $\begin{array}{l}\text { Number of } \\
\text { consultations }\end{array}$ & 330 & 378 & 257 & 317 & 304 & 186 & 208 & 269 & 238 & 263 & 1586 & 1164 \\
\hline $\begin{array}{l}\text { Price of a } \\
\text { consultation (lv.) }\end{array}$ & 109.5 & & & & & 8 & & & & & 109.5 & 8 \\
\hline $\begin{array}{l}\text { Subsidies for } \\
\text { outpatient care }\end{array}$ & 36135 & 41391 & 28142 & 34712 & 33288 & 1488 & 1664 & 2152 & 1904 & 2104 & 173667 & 9312 \\
\hline Public & 126 & 180 & 164 & 174 & 142 & 140 & 160 & 172 & 148 & 192 & 786 & 812 \\
\hline Private & 7 & 5 & 7 & 6 & 6 & 32 & 72 & 70 & 65 & 46 & 31 & 285 \\
\hline
\end{tabular}

Source: LSMS, Bulgaria

\section{F. Redistributive Effect of Health Care Payments}

Next step of the analysis will examine the influence of health care payments on the poverty level. There is no official poverty line in Bulgaria for the studied period but there are two official thresholds: the minimum wage-which is estimated to be a minimum on which a working person can live. The second one is the "cost of living" - this is an estimate of ITUSR which is published monthly and represents the results of the average monthly consumption of the population. The first threshold is trying to capture the effect of health care payments on the extreme poverty and the second one on relative deprivation. According to Townsend (1993) "people are relatively deprived if they cannot obtain, at all or sufficiently, the conditions of life - that is, the diets, amenities, standards and serviceswhich allow them to play the roles, participate in the relationships, and follow the customary behavior which is expected of them by virtue of their membership of society" (p. 36). ITUSR is using this approach for the construction of the cost-of-living parameter. The methodology is explained in detail by Ivanova (2003).

For the purpose of this analysis, the two thresholds are poverty and relative deprivation measures.

Table 6 compares the effect of health care spending on the poverty and relative deprivation in 1995 and 2001. In 2001 not only the number of people who are in poverty is larger (37 percent of the population in 2001 compared to 21 percent in 1995) but the poverty impact of health care payments is also larger. It doubles from 4 percent in 1995 to pushing additional 8 percent in poverty in 2001. Furthermore, the normalized gap (13) shows that the overshoot or the poverty is much more severe in 2001 and also the increase due to health care payments is larger: 8 percent compared to 3 percent in 1995. Similarly, the normalized mean positive poverty gap (14), representing the effect of the health care payments on the poor is much larger in 2001, piling on a starting NPG much higher in 2001. 
Table 6. Poverty Impact of Health Care Payments

\begin{tabular}{|c|c|c|c|c|c|}
\hline & \multicolumn{2}{|l|}{1995} & \multicolumn{2}{|l|}{2001} \\
\hline & & $\begin{array}{l}\text { Minimum } \\
\text { wage (2143) }\end{array}$ & $\begin{array}{l}\text { Cost of living } \\
(8086)\end{array}$ & $\begin{array}{l}\text { Minimum } \\
\text { wage (79) }\end{array}$ & $\begin{array}{l}\text { Cost of living } \\
(258)\end{array}$ \\
\hline \multirow[t]{3}{*}{ Headcount } & Prepayment & 0.21 & 0.93 & 0.37 & 0.92 \\
\hline & Postpayment & 0.25 & 0.94 & 0.44 & 0.92 \\
\hline & Poverty impact & 0.04 & 0.01 & 0.08 & 0.01 \\
\hline \multirow[t]{3}{*}{ Gap } & Prepayment & 193 & 4280 & 14 & 144 \\
\hline & Postpayment & 258 & 4464 & 20 & 156 \\
\hline & Poverty impact & 64.95 & 184.12 & 6.62 & 12.05 \\
\hline \multirow[t]{3}{*}{ Normalized gap } & Prepayment & 0.09 & 0.53 & 0.17 & 0.56 \\
\hline & Postpayment & 0.12 & 0.55 & 0.26 & 0.61 \\
\hline & Poverty impact & 0.03 & 0.02 & 0.08 & 0.05 \\
\hline \multirow{2}{*}{$\begin{array}{l}\text { Mean positive poverty } \\
\text { gap }\end{array}$} & Prepayment & 912 & 4600 & 37 & 157 \\
\hline & Postpayment & 1019 & 4767 & 46 & 169 \\
\hline \multirow{2}{*}{$\begin{array}{l}\text { Normalized mean } \\
\text { positive poverty gap }\end{array}$} & Prepayment & 0.43 & 0.57 & 0.46 & 0.61 \\
\hline & Postpayment & 0.48 & 0.59 & 0.58 & 0.66 \\
\hline
\end{tabular}

Source: LSMS, Bulgaria

The effect on the relative deprivation is much smaller, because a very high proportion of the population is below this threshold. Still, the overshoot in 2001 is significantly higher both for the poor and the population as a whole.

Figure 9 and Figure 10 show Pen's parade for pre- and post-payment income distribution in comparison to minimum wage for the two years. The figures present the changes in income distribution, underlining the negative effect of economic changes on poverty and the additional burden of health care payments which strengthens the problem.

The results show a clear increase in the number of people who are in poverty and in the level of poverty and reveal that the changes in the health care system financing have deepened the problem by bringing an increasing number of people under the minimum wage income. Additionally, the study examines the effect of these payments on income. 
Figure 9: Pen's parade of pre and post-health care payment's income, 1995

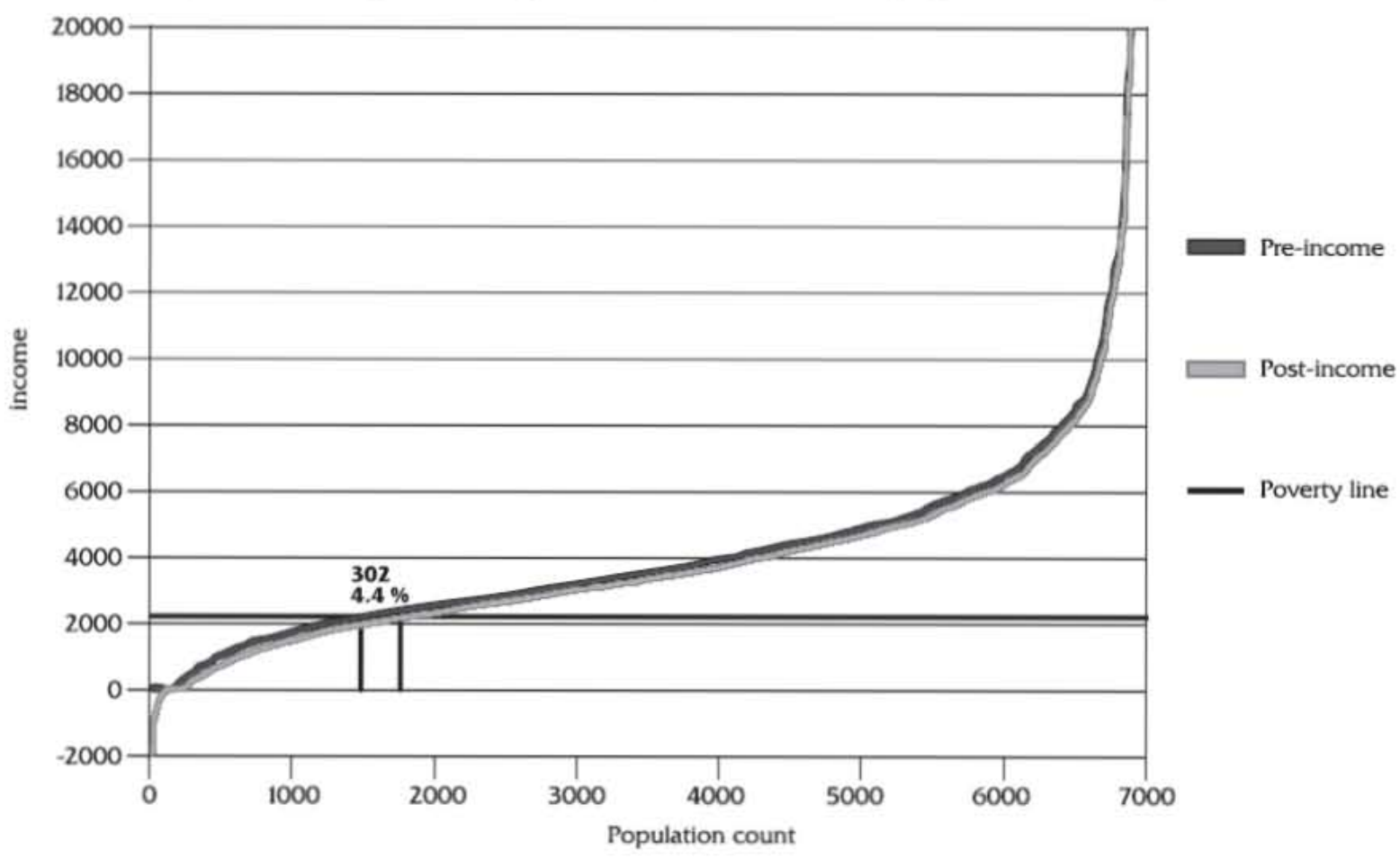

Source: LSMS, Bulgaria

Figure 10: Pen's parade of pre and post-health care payment's income, 2001

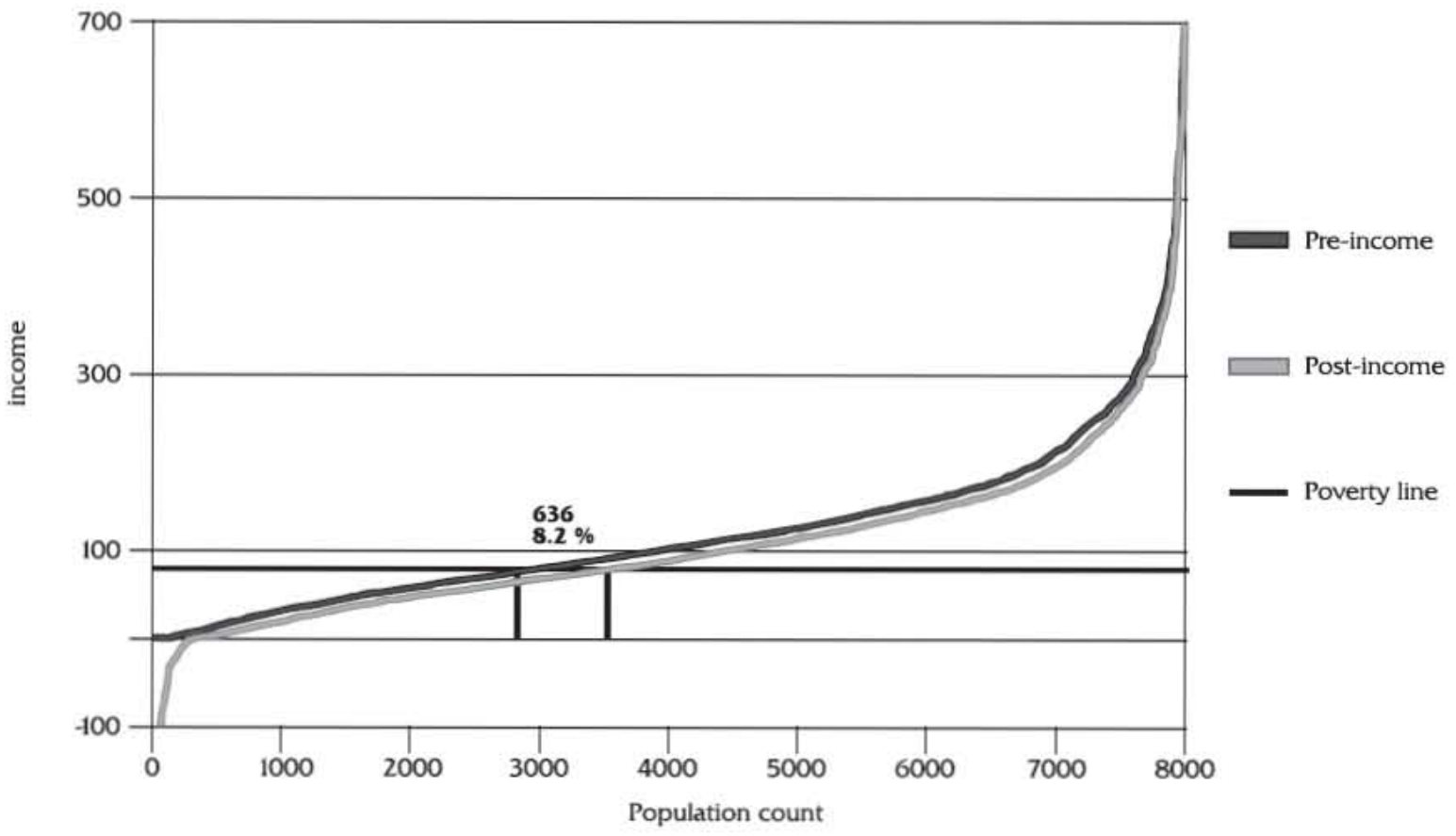

Source: LSMS, Bulgaria 
Figure 11 shows the distribution of proportion of income, which people spend on out-ofpocket payments and totally on health care. It is clearly visible that in 2001 people spent a much larger proportion of their income on health care and a much larger percentage of the population has proportionately larger spending. This underlines the increase in the share of health care expenditure from the disposable income and its impact on the economic wellbeing of the population.

Figure 11: Share of Income Spent on Health Care - Total and OOP

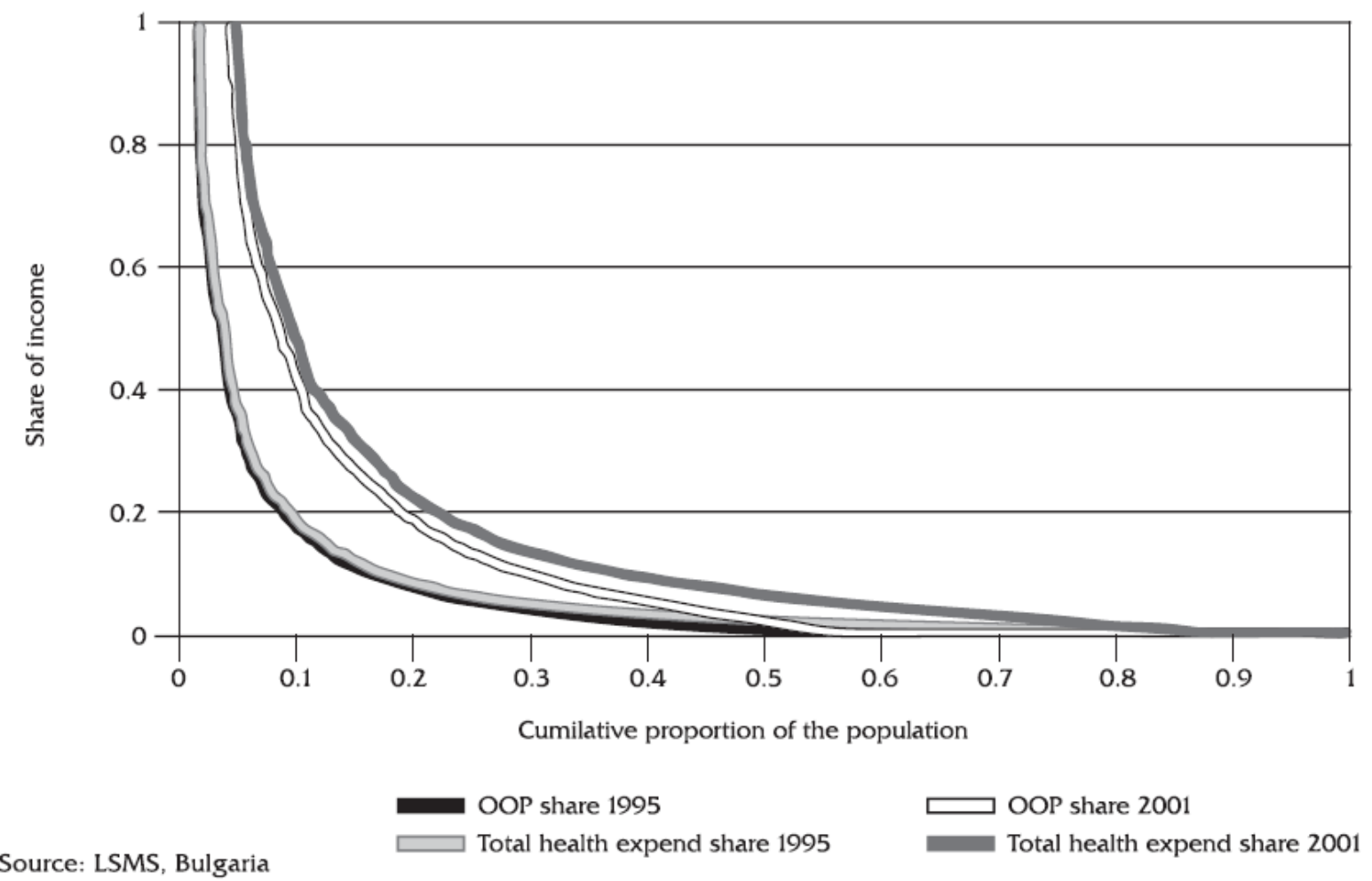

In order to look more closely at this pattern, the research examines the headcount and the gap for the people spending over a certain percentage of their income and the poverty weighted values of these coefficients $\Delta C$ shows the progressiveness/regressiveness of the health care payments only due to health care financing arrangements. The difference between the Gini coefficient and $\Delta C$ is then a measure of the economic equity (Ee) (7), (16), and (17). The study looks at the proportion of people who spend more than 5, 10, 15, 20, and 25 percent of their income on health care and how much more than these percentage they spend. As can be expected from the figure above the number of people for all thresholds is almost double in 2001. What is striking from the data is that the overshoot is on average four times larger in 2001 for all the thresholds. This shows that not only did twice as many people spend a similar percentage of their income on health care in 2001, but they also spent a much larger proportion of their income. 
Table 7: Catastrophic Health Care Payments

\begin{tabular}{|c|c|c|c|c|c|c|c|c|}
\hline & \multicolumn{5}{|c|}{ Health care expenditures as a percentage of income } \\
\hline & & & & $5 \%$ & $10 \%$ & $15 \%$ & $20 \%$ & $25 \%$ \\
\hline \multirow[t]{8}{*}{ Unweighted } & \multirow[t]{4}{*}{ OOP } & \multirow[t]{2}{*}{ Headcount } & 1995 & 0.27 & 0.18 & 0.13 & 0.10 & 0.08 \\
\hline & & & 2001 & 0.41 & 0.30 & 0.24 & 0.20 & 0.17 \\
\hline & & \multirow[t]{2}{*}{ Gap } & 1995 & 0.06 & 0.05 & 0.04 & 0.04 & 0.03 \\
\hline & & & 2001 & 0.22 & 0.20 & 0.19 & 0.18 & 0.17 \\
\hline & \multirow[t]{4}{*}{ Total } & \multirow[t]{2}{*}{ Headcount } & 1995 & 0.31 & 0.19 & 0.14 & 0.11 & 0.09 \\
\hline & & & 2001 & 0.54 & 0.36 & 0.27 & 0.21 & 0.18 \\
\hline & & \multirow[t]{2}{*}{ Gap } & 1995 & 0.06 & 0.05 & 0.04 & 0.04 & 0.03 \\
\hline & & & 2001 & 0.23 & 0.21 & 0.19 & 0.18 & 0.17 \\
\hline \multirow[t]{8}{*}{ Weighted } & \multirow[t]{4}{*}{ OOP } & \multirow[t]{2}{*}{ Headcount } & 1995 & 0.33 & 0.23 & 0.18 & 0.15 & 0.13 \\
\hline & & & 2001 & 0.45 & 0.36 & 0.30 & 0.26 & 0.23 \\
\hline & & \multirow[t]{2}{*}{ Gap } & 1995 & 0.09 & 0.07 & 0.07 & 0.06 & 0.05 \\
\hline & & & 2001 & 0.35 & 0.33 & 0.32 & 0.30 & 0.29 \\
\hline & \multirow[t]{4}{*}{ Total } & \multirow[t]{2}{*}{ Headcount } & 1995 & 0.37 & 0.24 & 0.19 & 0.16 & 0.14 \\
\hline & & & 2001 & 0.55 & 0.41 & 0.33 & 0.27 & 0.24 \\
\hline & & \multirow[t]{2}{*}{ Gap } & 1995 & 0.09 & 0.08 & 0.07 & 0.06 & 0.06 \\
\hline & & & 2001 & 0.36 & 0.34 & 0.32 & 0.31 & 0.30 \\
\hline \multirow{8}{*}{$\begin{array}{l}\text { Concentration } \\
\text { index for the } \\
\text { unweighted }\end{array}$} & \multirow{4}{*}{ OOP } & \multirow[t]{2}{*}{ Headcount } & 1995 & -0.22 & -0.32 & -0.38 & -0.45 & -0.55 \\
\hline & & & 2001 & -0.10 & -0.20 & -0.27 & -0.31 & -0.35 \\
\hline & & \multirow[t]{2}{*}{ Gap } & 1995 & -0.51 & -0.58 & -0.62 & -0.67 & -0.70 \\
\hline & & & 2001 & -0.62 & -0.66 & -0.69 & -0.71 & -0.74 \\
\hline & \multirow[t]{4}{*}{ Total } & \multirow[t]{2}{*}{ Headcount } & 1995 & -0.18 & -0.30 & -0.37 & -0.43 & -0.51 \\
\hline & & & 2001 & -0.01 & -0.15 & -0.23 & -0.28 & -0.33 \\
\hline & & \multirow[t]{2}{*}{ Gap } & 1995 & -0.50 & -0.57 & -0.62 & -0.66 & -0.70 \\
\hline & & & 2001 & -0.58 & -0.64 & -0.68 & -0.70 & -0.72 \\
\hline
\end{tabular}

Source: LSMS, Bulgaria

When people are weighted on their poverty relevant ranks (16) and (17) data suggests that the health care burden predominantly influences the poorer people. Nevertheless, this effect is much stronger in 1995 than in 2001. People who spend a higher proportion of their income in 1995 are concentrated much more in the lower-income groups than in 2001. This might be either a result from abstention of the poor from health care use or increase of health care spending amongst the rich. If we consider that the overshoot is much more concentrated amongst the poor in 2001 we can presume that this positive tendency is rather a result from nonutilization of health services amongst the poor, which we have already observed. 


\section{CONCLUSION ${ }^{9}$}

One of the aims of the introduction of a health care insurance system in Bulgaria in 2000 was to improve the equity in the provision of health care. The equity goal of the reform is a changing multivariate one. It depends on the income distribution in the society, which defines the ability of the population to buy health care services, changes in the social arrangements, and the health care system itself.

During the six-year period under study, income inequality has grown very substantially. This has increased the role of the health care system in building "medical insurance guaranteeing them (the citizens) affordable medical care" (Constitution of Republic of Bulgaria, 1991, Article 52, s.a. 1). The income inequality has also made it more difficult to reach financing adequate to the ability of the people to pay and financial access to the system, which will allow adequate delivery for those in need.

The financing of the health insurance system has gradually moved away from financing from the general budget. The aim was to ensure stable financing of the sector. Furthermore, the changes in the financing of the health care have included significant efforts to regulate outof-pocket payments, which are the most regressive system of financing. Nevertheless, out-ofpocket payments have remained the major means of financing. This has maintained a high financial impact at the point of need and on the use of services, which makes the occurrence of health risks a significant financial burden. After the health sector reforms these occurrences have had a less severe effect on the income of the poor. This tendency is not necessarily positive, because it appears to be shaped not by choice but by affordability. It will still be an overstatement if the success of the reform in the financing of the sector is discussed without considering that health insurance is only 6 percent of health care expenses. The only way to gain significant results will be to increase the proportion of insurance-based financing, and decrease the level of out-of-pocket payments.

After the reforms, the progressiveness of the out-of-pocket payments to the income more than doubled. Additionally, the proportion of tax payments has also increased. These two factors have made the progressiveness of total health care spending much higher. However, this increase has been insufficient to compensate for the increase in income inequality. As a result, financing of the health insurance system has been more regressive in relation to the income than prior to reforms. Financial equity has decreased over the time period. Still, for the poor in 2001, the distribution of health care expenditures has reflected the distribution of income much more accurately. This means that health care expenses have not been such a burden for the worse-off as they were before the reforms. Nonetheless, one has to be careful when judging the changes in health care expenditures. Their decrease for the poor would be clearly a positive trend only if all of the other factors were kept constant, particularly the utilization of the services. In this case the positive effect is dubious because the goal has been reached by paying the price of nontreatment, which can have a much worse effect.

\footnotetext{
${ }^{9}$ The conclusions drawn from the data are to relate to the first 3 years of the health care reform in Bulgaria. The paper's findings might be altered if more current data were available.
} 
Methodologically, the division of the concentration coefficient into income and nonincome factors leads to several important conclusions. First, the increase in the progressivity of health care payments is not a positive factor if it is due to abstention from use of health care by specific social groups. This leads to further social exclusion. Only an understanding of the reasons for this exclusion can help the system to reach the excluded. Second, the only way to consider the equity of health care financing is by looking at the economic equity. Thus, social-status-related factors can be eliminated so that fair decisions about the financing of the system may be made.

The changes in the progressiveness of health care expenses are due to the increase in the proportionality of health care payments to income and to changes in the willingness of the different social categories to pay for health care. Both factors have had a positive effect over time. In other words, health care spending distribution has been closer related to the income distribution but also some social groups who are poorer are on average spending less on health care. This means that health care payments are less proportionate to income levels due to the system arrangements than it actually appears. Another conclusion from this analysis is that there are social characteristics which prevent part of the society from using health care. Usually, this is connected to social factors which are associated with lower social class. A notable difference exists within the Roma population. There has been a substantial increase in the health care spending differences between this group and the rest of the population over time. The results suggest that the health care reforms have created a system, which is even more exclusive for this ethnic group. The reforms have had the opposite effect on the Turkish minority, by making the system more inclusive for them, regardless of the overall impoverishment of the group.

Another factor has been the level of education. Less educated people have been much less likely to spend on health care after the reforms. Another problem appears to be regional inequalities. There are substantial discrepancies amongst the geographic regions, which is most likely a result of spatial inequalities in service provision. These findings suggest that the system has increased the social exclusion of particular groups, which are already socially deprived. This presumes that there might be a need for additional targeted programs.

As has already been suggested, over time there has been an income related decrease in the usage of health care. After the reforms, the affordability problem has grown and has developed a very clear link to the level of income. In other words, the poor cannot afford to use health care as much as the rich. As a result, public expenditure on health care mainly benefits the rich. Therefore, considering the regressive character of health care financing, and adding the progressive effect of health care subsidies, the health insurance system has had a very regressive redistributive effect on the purchasing power of the population.

Furthermore, the effect of health care financing has much more regressive redistributive effect on the income. In 2001 not only a larger proportion of the population was poor before making health care payments, but making these payments increased that proportion much more. Besides, the proportion of the income spent on health care also increases. This tendency is very significant among the low-income groups. What is particularly striking is that the increased burden, or the actual proportion of the income spent on health care, is on 
average about four times larger in 2001. This also mainly influences people from the lower range of the income distribution. Nevertheless, the effect of these very high expenses in 1995 influences the poorer more. After the reforms a smaller proportion of poor people spend a high proportion of their income for health care, but when they do this, it is a much larger burden for them. This can explain why an increasing percentage of them choose not to use health care services while needing them.

In conclusion, it appears that the introduction of health care insurance has not improved the equity of health care financing. Both from the financing and delivery perspectives, the problems have deepened. Even though the main problems for financing of the health care system come from the increase in overall impoverishment of the population, the system has not been able to develop "safe ways" for the poor to enter. The main problem is the increase in the number of people unable to afford health care services and the impoverishment effect for those who use them. This tendency leaves lower-income groups with a choice of extreme poverty or untreated illness. A particularly disturbing result is the increase in the discrepancies of health care use amongst different social groups. These tendencies push parts of the society with specific social characteristics into the poverty trap and so create a base for long-term ethnic and social problems. Therefore, future changes in the health care system have to take into account these deepening problems and adopt targeted programs for the excluded groups. Only then can the system prevent negative long-term consequences.

These findings cannot be left out of the context of the ongoing health care reform. As in regard to 2006 one of the biggest problems still is the prolonged reform in the inpatient sector which is one of the biggest drains both public and private health care resources. The regulation of this sector can decrease substantially the out-of-pocket payments and stabilize the system by freeing financial resource which can be used more effectively. Further reforms can benefit more not from increase in public spending, but from regulation of out-of pocket expenses. Thus, the positive results of the organizational reform for the equity objective can overcome the problems. Moreover, there should be given special attention to the ongoing process of social segregation of the health care use and there should be developed special "inclusion" programs which can allow the reform to reach those who have not found their way in. 


\section{References}

Anand, S., F. Diderichsen, T. Evans, V. Shkolnikov, and M. Wirth, 2001, "Measuring Disparities in Health: Methods and Indicators." in Challenging Inequities in Health: From Ethics to Action, ed. by T. Evans, M. Whitehead, F. Diderichsen, and others, (Oxford: Oxford University Press).

Atanasov, A., Z. Toneva, and others, 2002, Health Care Expenditures of the Households. Sofia, Bulgarian Science Academy. Sociology institute.

Balabanova, D., M. Bobak, and M. McKee, 1998, "Patterns of Smoking in Bulgaria," Tobacco Control, Vol. 7, No. 4, pp. 383-385.

Balabanova, D., and M. McKee, 2002a "Understanding Informal Payments for Health Care: The Case of Bulgaria," Health Policy, Vol. 62, pp. 243-273.

— 2002b, "Access to Health Care in a System Transition: The Case of Bulgaria." Health Policy, Vol. 17, pp. 377-395.

Claeson, M., C. Griffin, T. Johnson, M. McLachlan, A. Soucat, A. Wagstaff, and A. Yazbeck, 2002, "Health, Nutrition and Population," in A Sourcebook for Poverty Reduction Strategies, ed. by J. Klugman, pp. 201-230, (Washington: World Bank).

Constitution of Republic of Bulgaria, State Gazette (Republic of Bulgaria),1991, Vol. 56, 1991; 13 July.

Cowell, FA., 1995, Measuring Inequality. (London: Prentice Hall/Harvester Wheatsheaf, $2^{\text {nd }}$ ed.).

Delcheva, E., D. Balabanova, and M. McKee, 1997, "Under-the-Counter Payments for Health Care," Health Policy, Vol. 42, pp. 89-100.

Gillon, R., 1986, Philosophical Medical Ethics, (Chichester: Wiley),

Gravelle, H., 2003, "Measuring Income Related Inequality in Health: Standardisation and the Partial Concentration Index." Health Policy, Vol. 12, pp. 803-819.

Hutton, G., 2002, Equity and Access in the Health Sector in 5 Countries of E. Europe and Central Asia (Sweden: Swees Tropical Institute).

Institute for Trade Union and Social Research, 2004, "Cost of Living per Household and Average per One Person for June 2000-2004,” Living Standards, Vol. 2, No. 41.

Ivanova, V., 2003, Metodika za Opredeliane Praga na Bednostta na ISSI na KNSB (Sofia: Institute for Trade Union and Social Research). 
Kakwani, N., 1977a, "Applications of Lorenz Curves in Economic Analysis," Econometrica: Journal of the Econometric Society, Vol. 45, pp. 719-727.

_ $1977 \mathrm{~b}$, "Measurement Of Tax Progressivity: An International Comparison." The Economic Journal, Vol. 87, No. 1, pp. 71-80.

_ 1980, Income Inequality and Poverty: Methods of Estimation and Policy Applications, (New York, Oxford: Published for the World Bank by Oxford University Press).

— A. Wagstaff, and E.Van Doorslaer, 1997, "Socioeconomic Inequalities in Health: Measurement, Computation, and Statistical Inference.” Health Policy, Vol. 77, pp. 7103.

Koolman, X., and E. Van Doorslaer, 2004, "On the Interpretation of a Concentration Index of Inequality." Health Economics, Vol. 13, No. 7, pp. 649-656.

Koulaksazov, S., S. Todorova, S. Hristova, S., 2003, in Health Care Systems in Transition, ed. by Tragakes, Available via the Internet: http://www.euro.who.int/document/e81760.pdf

Machenback and Kunst 1997, "Measuring the Magnitude of Socio-Economic Inequalities in Health: An Overview of Available Measures Illustrated with Two Examples from Europe," Social Science and Medicine, Vol. 44, pp. 757-771.

Mahalnobis, PC., 1960, "A Method of Fractile Graphical Analysis.” Econometrica: Journal of the Econometric Society, Vol. 28, pp.325-351.

Marmot 2001, "Income Inequality, Social Environment, and Inequalities in Health," Journal of Policy Analysis and Management, Vol. 20, pp. 156-159.

McLachlan, G., A. Maynard, A.J. Culyer, and Nuffield Trust for Research and Policy Studies in Health Services, 1982, The Public/Private Mix for Health: The Relevance and Effects of Change: Essays, (London: Nuffield Provincial Hospitals Trust).

Minev, D., B, Dermendjieva, and N. Mileva, 1990, "The Bulgarian Country Profile: The Dynamics of Some Inequalities in Health," Social Science \& Medicine, Vol. 31, No. 8, pp. 837-846.

Ministry of Health, 2001, "Better Health for a Better Future of Bulgaria," in National Health Strategy (Sofia: Republic of Bulgaria).

National Framework Contract, 2000, in Series National Framework Contract, State Gazette (Republic of Bulgaria), Vol. 42, 23 May 2000, p. 23. 
National Statistical Institute, 2004, Osnovni Rezultati ot Izsledvaneto na Domakinskite Budjeti Prez, Available via the Internet:

http://www.nsi.bg/budgetHome/BudgetHome03t.htm

NCHI and Ministry of Health, 1996, Overview: Ikonomika v Zdraveopazvaneto, 7.

Pavlova, M., W. Groot, and G. Van Merode, 2002, "Public Attitudes Towards Patient Payments," Health Policy, Vol. 59, No. 1, pp. 1-24.

_ 2003, "The Importance of Quality, Access and Price to Health Care Consumers in Bulgaria a Self-explicated Approach,” Health Policy, Vol. 18, pp. 343-361.

Schokkaert, E., and C. Van de Voorde, 2004, "Risk Selection and the Specification of the Conventional Risk Adjustment Formula," Journal of Health Economics, Vol. 23, No. 6, pp.1,237-1,259.

Sen, A.K., 2003 Inequality Reexamined (New York: Oxford University Press).

Smith and Egger 1996, "Income Inequality, Social Environment, and Inequalities in Health," Journal of Policy Analysis and Management, Vol. 20, pp. 156-159.

Thompson, R., and S. Witter, 2000, "Informal Payments in Transitional Economies: Implications for Health Sector Reform.” Health Policy, Vol. 15, pp. 169-187.

Townsend, P. and Michael Harrington Center for Democratic Values and Social Change, 1993 The International Analysis of Poverty (New York ; London, Harvester Wheatsheaf).

Uitenbroek, DG., A. Kerekovska, and N. Festchieva, 1996, "Health Lifestyle Behaviour and Socio-demographic Characteristics: A Study of Varna, Glasgow and Edinburgh," Social Science \& Medicine, Vol. 43, No. 3, pp. 367-377.

United Nations, 2005, "Inequality Database," Available via the Internet: http://www.wider.unu.edu/wiid/wiid.htm.

Van Doorslaer, E., and A.M. Jones, 2004a, "Income-Related Inequality in Health and Health Care in the European Union," Health Economics, Vol. 13, No. 7, pp. 605-608.

_ 2004b, "Explaining Income-Related Inequalities in Doctor Utilisation in Europe," Health Economics, Vol. 13, No. 7, pp. 629-647.

Van Doorslaer, E., and X. Koolman, 2004b, "Explaining the Differences in Income-related Health Inequalities Across European Countries," Health Economics, Vol. 13, No. 7. pp. 609-628. 
Van Doorslaer, E., and A.M. Jones, 2003, "Inequalities in Self-reported Health: Validation of a New Approach to Measurement," Journal of Health Economics, Vol. 22, No. 1, pp. 61-87.

Van Doorslaer, E., X. Koolman, and F. Puffer, 2002, "Equity in the use of Physician Visits in OECD Countries: Has Equal Treatment for Equal Need Been Achieved?" OECD (Ed), Measuring Up: Improving Health System Performance in OECD Countries. (Paris: OECD), pp. 225-248.

Van Doorslaer, E., A. Wagstaff, and F.F.H. Rutten, 1993, Equity in the Finance and Delivery of Health Care: an International Perspective, (Oxford: Oxford University Press).

Wagstaff, A., E. Van Doorslaer, and P. Paci, 1989 "Equity in Finance and Delivery of Health Care: Some Tentative Cross-Country Comparisons," Oxford Review of Economic Policy, Vol. 5, No. 1, pp. 89-112.

Wagstaff, A., and E.Van Doorslaer, 1998, "Equity in Health Care Financing and Delivery." in North Holland Hand Book of Health Economics, ed. by A. Colyer (Draft).

Wagstaff, A., E. Van Doorslaer, H. Van der Burg, S. Calonge, T. Christiansen, G. Citoni, U.G. Gerdtham, M. Gerfin, L. Gross, U. Hakinnen, P. Johnson, J. John, J. Klavus, C. Lachaud, J. Lauritsen, R. Leu, B. Nolan, E. Peran, J. Pereira, C. Propper, F. Puffer, L. Rochaix, M. Rodriguez, M. Schellhorn, O. Winkelhake, et al., 1999, "Equity in the Finance of Health Care: Some Further International Comparisons," Journal of Health Economics, Vol. 18, No. 3, pp. 263-290.

Wagstaff, A., E. Van Doorslaer, and N. Watanabe, 2003a, "On Decomposing the Causes of Health Sector Inequalities with an Application to Malnutrition in Vietnam," Journal of Econometrics, Vol. 112, pp. 207-223.

_ 2003b, "Catastrophe and Impoverishment in Paying for Health Care: With Applications to Vietnam, 1993-1998," Health Economics, Vol. 12, No. 11, pp. 921934.

World Bank, 2004a, The Concentration Index, Available via the Internet: http://web.worldbank.org/WBSITE/EXTERNAL/TOPICS/EXTHEALTHNUTRITIO NANDPOPULATION/EXTPAH/0, contentMDK:20216933 menuPK:400482 page PK:148956 piPK:216618 theSitePK:400476,00.html. , 2004b, "Concentration Curves," Available via the Internet: http://web.worldbank.org/WBSITE/EXTERNAL/TOPICS/EXTHEALTHNUTRITIO NANDPOPULATION/EXTPAH/0,,contentMDK:20216933 menuPK:400482 page PK:148956 piPK:216618 theSitePK:400476,00.html. 
2004c, "Measuring Standardized Health Distributions," Available via the Internet: http://web.worldbank.org/WBSITE/EXTERNAL/TOPICS/EXTHEALTHNUTRITIO NANDPOPULATION/EXTPAH/0,,contentMDK:20216933 menuPK:400482 page PK:148956 piPK:216618 theSitePK:400476,00.html.

—, $2004 d$, "Benefit Incidence Analysis," Available via the Internet: http://web.worldbank.org/WBSITE/EXTERNAL/TOPICS/EXTHEALTHNUTRITIO NANDPOPULATION/EXTPAH/0,,contentMDK:20216933 menuPK:400482 page PK:148956 piPK:216618 theSitePK:400476,00.html.

—, $2004 \mathrm{e}$, "Measuring Inequity in Health Service Delivery," Available via the Internet: http://web.worldbank.org/WBSITE/EXTERNAL/TOPICS/EXTHEALTHNUTRITIO NANDPOPULATION/EXTPAH/0,,contentMDK:20216933 menuPK:400482 page PK:148956 piPK:216618 theSitePK:400476,00.html.

2004f, "Catastrophic Health Care Payments," Available via the Internet: http://web.worldbank.org/WBSITE/EXTERNAL/TOPICS/EXTHEALTHNUTRITIO NANDPOPULATION/EXTPAH/0,, contentMDK:20216933 menuPK:400482 page PK:148956 piPK:216618 theSitePK:400476,00.html.

, 2004g, "Poverty Impact of Health Care Payments," Available via the Internet: http://web.worldbank.org/WBSITE/EXTERNAL/TOPICS/EXTHEALTHNUTRITIO NANDPOPULATION/EXTPAH/0,, contentMDK:20216933 menuPK:400482 page PK:148956 piPK:216618 theSitePK:400476,00.html. 